\title{
Construction of a Protoglomerular Template by Olfactory Axons Initiates the Formation of Olfactory Glomeruli in the Insect Brain
}

\author{
Lynne A. Oland, Galya Orr, and Leslie P. Tolbert \\ Arizona Research Laboratories, Division of Neurobiology, University of Arizona, Tucson, Arizona 85721
}

\begin{abstract}
Olfactory glomeruli in insects share many features of organization with their vertebrate counterparts, and yet offer distinct advantages for study of neuronal development. Previous studies have revealed that the olfactory lobes of the brain of the moth Manduca sexta arise postembryonically and that glomeruli in the lobe are induced by olfactory afferent axons (Hildebrand et al., 1979; Oland and Tolbert, 1987). In the present study, we have used the Golgi method, intracellular labeling of neurons with Lucifer yellow, and electron microscopy to follow neuronal development in the antennal lobe through the period when glomeruli develop. Our results, taken together with other results from our laboratory, suggest that olfactory sensory axons have the intrinsic ability to form protoglomeruli, and that an interaction between these axons and glial cells (but not the majority of the neurons of the antennal lobe) causes the glial cells to surround the protoglomeruli. Ingrowth of the neurites of most antennal-lobe neurons into the protoglomeruli occurs after a small delay and appears to be constrained to glomerular units by the presence of the glial boundaries. Synapses, initially not detected in the protoglomeruli, begin to appear as soon as the neurites of antennal-lobe neurons appear in the glomeruli. Thus, antennal axons, instead of immediately seeking out postsynaptic targets, first form the template for organization of future glomeruli. The neurites of most of the neurons of the antennal lobe grow outward to meet the olfactory sensory axons, and in doing so, join with these axons to form glomeruli.

Preliminary results concerning the development of a second class of neuron in the lobe, the projection neurons, indicate that at least some of these neurons may arborize in the region of the protoglomeruli very early and therefore participate with the afferent axons in laying the foundation for glomeruli.
\end{abstract}

The branching pattern of a neuron is fundamentally important because it defines the spectrum of potential synaptic partners and shapes the neuron's integrative properties. During devel-

\footnotetext{
Received Nov. 8, 1989; revised Dec. 26, 1989; accepted Jan. 4, 1990.

We wish to thank Chip Hedgecock for preparing the final photographic plates, and Drs. Jon Hayashi and Paul St. John for many helpful discussions during the course of this work and for critical reading of the manuscript. This work was supported by NIH grant NS-20040 to L.P.T.

Correspondence should be addressed to Dr. Lynne A. Oland, Arizona Research Laboratories, Division of Neurobiology, 634 Gould-Simpson Building, University of Arizona, Tucson, AZ 85721 .

Copyright (C) 1990 Society for Neuroscience $0270-6474 / 90 / 072096-17 \$ 03.00 / 0$
}

opment, interactions with other cells can influence branching patterns of neurons in both vertebrates (Rakic and Sidman, 1973; Goodman et al., 1988; Deitch and Rubel, 1989) and invertebrates (Murphey et al., 1975; Hoy et al., 1978; Macagno, 1979; Anderson et al., 1980; Shankland et al., 1982; Schildberger et al., 1986). The mechanisms underlying these effects are not known in detail, although, generally speaking, neurites seem to grow toward sources of synaptic input and to be "stabilized" by the formation of synapses.

In this study, we have focused on cellular interactions that influence the morphological differentiation of neurons in the developing olfactory (antennal) lobe of the moth Manduca sexta, a system with distinct technical advantages for the study of neuronal differentiation. Advantages are that: the antennal system arises postembryonically, during the metamorphosis from larva to moth, when the animal is readily manipulated experimentally; the sensory neurons arise and develop at a distance from their postsynaptic targets and so can be removed easily (Sanes et al., 1977); and the organization (Homberg et al., 1989) and development (Hildebrand, 1985; Oland and Tolbert, 1987; Tolbert and Oland, 1989) of the lobe are understood in some depth. Whereas the vertebrate olfactory bulb simply fails to develop in the absence of olfactory sensory axons (reviewed by Brunjes and Frazier, 1986), antennal sensory axons in the metamorphosing moth induce glomeruli in a structure that continues to develop many normal features even in the absence of the axons (Hildebrand et al., 1979; Oland and Tolbert, 1987). In combination, these advantages permit us to ask specific, detailed questions about cellular interactions critical in development.

Like other first-order olfactory centers throughout the animal kingdom (e.g., Bullock and Horridge, 1965; Shepherd, 1970; Hildebrand et al., 1979; Graziadei and Samanen, 1980; Northcutt and Braford, 1980), the antennal lobe of the moth is distinguished histologically by the presence of glomeruli. Evidence from several systems, including the moth, suggests that glomeruli may be the anatomical substrates for odor-specific information processing (Sharp et al., 1977; Chambille et al., 1980; Matsumoto and Hildebrand, 1981). In the moth, glomeruli are roughly spheroidal regions of neuropil that comprise the terminal arborizations of about 300,000 (Oland and Tolbert, 1988) afferent olfactory axons and the dendrites of approximately 1200 (Homberg et al., 1989) antennal-lobe neurons. There are 57-61 glomeruli (Schneiderman et al., 1983). Virtually all synaptic interactions in the lobe occur in the glomeruli (Tolbert and Hildebrand, 1981). A few (approximately 20-40) neurons from other regions of the brain also terminate in the glomeruli (Kent, 1985; Kent et al., 1987; Homberg et al., 1988). Layers of glial processes, readily recognized in both the light and electron mi- 
croscopes, form partitions between ncighboring glomeruli and demarcate the external boundaries of individual glomeruli.

Neurons of the antennal lobe fall into 2 classes (Homberg et al., 1989). Approximately one-third of the neurons are local interneurons, which generally form tufted arbors in most or all of the glomeruli. The interneurons generally receive direct input from antennal sensory axons and are involved in local interactions in the lobe (Christensen and Hildebrand, 1987b). Projection neurons, constituting two-thirds of all antennal-lobe neurons, more typically arborize in one or a few glomeruli and send an axon out of the lobe to protocerebral centers; although there is evidence that some projection neurons may receive direct sensory input (T. A. Christensen, personal communication), input to these neurons from the afferent axons is usually indirect. Using the numbers given above, a rough calculation suggests that each glomerulus will contain, on average, the processes of perhaps 300 local interneurons and the processes of perhaps 12 projection neurons.

The antennae and antennal lobes develop during the metamorphosis from larva to moth. Until stage 4 of the 18 stages of metamorphic adult development, the antennal lobe contains a small central ball of homogeneously textured neuropil surrounded by a single-cell-thick rind of glial cells. The cell bodies of the antennal-lobe neurons lie outside the glial rind. Previous studies of cellular interactions during development of the antennal lobe have shown that the presence of glomeruli in mature lobes requires both sensory axons from the antenna and neuropil-associated glial cells. In normally afferented antennal lobes, the arrival of antennal axons induces glial cells to extend processes and migrate toward the center of the neuropil, eventually forming the glomerular boundaries within which neuritic processes arborize (Oland and Tolbert, 1987). If most or all of the antenna is removed early in metamorphosis, the neuropil of the antennal lobe fails to become glomerular, instead differentiating only so far as to develop a central region of coarse neuropil surrounded by a ring of fine-textured neuropil (Hildebrand et al., 1979; Oland and Tolbert, 1987; Tolbert and Sirianni, 1990). The glial cells remain in their immature configuration as a thick border around the neuropil. We have hypothesized that the lack of glomeruli in deantennated lobes results, at least in part, from the absence of the signal(s) normally provided to glial cells by ingrowing afferent axons; that signal induces the glia to undergo the shape and positional changes that lead to formation of glomerular septa (Oland and Tolbert, 1987; Tolbert and Sirianni, 1990). To test for the role of glial cells in formation of glomeruli, lobes were generated that received afferent input but developed in the presence of a severely reduced population of glial cells. The resultant lobes also lacked glomeruli (Oland et al., 1988; Oland and Tolbert, 1989). This appears to be a consequence of having an insufficient number of glial cells to provide either the structures within which the newly emerging glomeruli develop or the stabilizing influence necessary for the maintenance of new glomeruli (Tolbert and Oland, 1990).

The current study was designed to determine how glial cells and the neurons whose arbors constitute adult glomeruli interact during the initial shaping of glomeruli. We show that construction begins with the arrival at the nascent lobe of fascicles of sensory axons that subsequently are deployed around the outside edge of the neuropil and form protoglomeruli. The protoglomeruli consist predominantly of knots of terminal arbors of sensory axons that become enveloped by glial cells; they may also contain the arbors of some projection neurons. The protoglomeruli do not appear to contain synapses. Adult glomeruli emerge as the processes of the rest of the central neurons invade the protoglomeruli, acquire their distinctive glomerular shape, and form synapses.

Some of these results have been reported in an abstract (Oland et al., 1989).

\section{Materials and Methods}

Animals. Manduca sexta (Lepidoptera: Sphingidae) were reared from eggs as described by Sanes and Hildebrand (1976). Metamorphic adult development proceeds over 18 stages, each lasting $1-4 \mathrm{~d}$, beginning at the time of pupation and ending with the emergence of the adult moth. The developmental stage of a metamorphosing animal was determined as in our previous study (Oland and Tolbert, 1987) by observation of morphological changes of the cuticle or of changes visible through the cuticle.

Removal of afferent innervation. To produce "deantennated" antennal lobes, the antennal anlagen were removed within $6 \mathrm{hr}$ after the larvalto-pupal molt by opening at its point of origin on the head the cuticle forming the antennal trough, scraping the inside of the trough to remove the presumptive antennal tissue, and filling the opening into the head with melted wax to prevent axons from the more distal portions of the future antenna from reaching the head. In some animals, the antennal anlage was removed from one side; in others, from both sides. Because the antenna contributes the overwhelming majority of afferent input to the lobes (Sanes and Hildebrand, 1976), deantennation removes all primary sensory input, except for a minor input from the labial pit organs (Kent et al., 1986).

Electron microscopy. Animals were anesthetized by cooling on ice. Each brain was removed from the head with the tissue surrounding it, gently scparated from the muscle and cuticular tissue, and immersed in cold fixative solution overnight. The fixative solution usually contained $2.5 \%$ glutaraldehyde, $0.5 \%$ paraformaldehyde, $0.18 \mathrm{~mm} \mathrm{CaCl}_{2}, 0.58 \mathrm{~mm}$ sucrose, and $0.1 \mathrm{M}$ sodium cacodylate buffer, $\mathrm{pH} 7.4$ (modified from Karnovsky, 1965). In some cases, tissue was prepared with tannic acid fixative containing $2.0 \%$ glutaraldehyde, $2.0 \%$ paraformaldehyde, $0.1 \%$ tannic acid, $0.25 \%$ DMSO in $0.1 \mathrm{M}$ cacodylate, $\mathrm{pH} 7.4$ (Anderson and Tucker, 1989). The brains were osmicated (1.0\%) en bloc, postfixed in $1.0 \%$ uranyl acetate, dehydrated through a graded series of ethanols, and embedded in Epon/Araldite. Thin sections were stained with lead citrate and examined in a JEOL $1200 \mathrm{EX}$ electron microscope. Adjacent thick (1- $\mu \mathrm{m}$ or $150-\mathrm{nm})$ sections were stained with toluidine blue to aid in localizing the region of interest for electron microscopy.

For each of the antennal lobes in which a portion of the developing ncuropil was cxamincd in detail, a montage of a complete protoglomerulus and the subjacent ring of fine-textured neuropil (stage $6, n=5$ ) or of a complete glomerulus (stages 7-8, $n=2$ each) was constructed from electron micrographs. One of the stage- 6 antennal lobes came from an animal of a different colony, but as we searched for but could not detect differences among the lobes, this animal is included in the reported results. A montage of a stage-12 glomerulus also was constructed for comparison of material from younger stages with a stage by which glomeruli appear histologically mature. Each montage was then mapped to indicate the location of glial processes and synapses. A junction was scored as a "definite" synapse if at least 3 synaptic vesicles, a presynaptic density, a widened cleft, and a postsynaptic density were present. If the presynaptic density was missing or the structure of the cleft and postsynaptic density was indistinct either because the junction was sectioned tangentially or pcrhaps because some of the features characteristic of mature junctions had not yet fully developed, the junction was scored as a "probable" synapse.

In order to look for junctions between neurons and glial cells, additional montages were made along the glial border where afferent axons traveling around the perimeter of the lobe dive through the glial border [stage 3 (prior to the arrival of antennal axons), $n=3$; stage $4, n=4$; stage $5, n=4$; stage $6, n=3$; stage $7, n=4$ ].

Lucifer yellow labeling of antennal-nerve axons. Brains were removed from the heads and placed in modified Sattelle's saline (Matsumoto and Hildebrand, 1981) in 35-mm Petri dishes. Stage-4 brains were prefixed with the fixative solution described below for $10-40 \mathrm{~min}$ to prevent inadvertent damage to the tiny antennal nerve. For all stages, the distal end of the antennal nerve, which had been cut as long as possible, was 


\begin{tabular}{|c|c|c|c|c|c|c|c|}
\hline Stage & Normal & Deantennated & $\begin{array}{l}\text { Bilaterally } \\
\text { deantennated* }\end{array}$ & Stage & Normal & Deantennated & $\begin{array}{l}\text { Bilaterally } \\
\text { deantennated }\end{array}$ \\
\hline 3 & - & - & 7 & 9 & 1 & - & 3 \\
\hline 4 & 7 & - & 1 & 10 & - & - & 1 \\
\hline e5 & 3 & - & 1 & 11 & - & - & 7 \\
\hline 5 & 9 & - & 8 & 12 & - & - & 15 \\
\hline e6 & 7 & - & - & 13 & - & 1 & 1 \\
\hline 6 & 2 & - & 5 & 14 & 3 & - & 8 \\
\hline 7 & 1 & - & 1 & 15 & 2 & 3 & - \\
\hline \multirow[t]{2}{*}{8} & - & - & 6 & 16 & 1 & - & 3 \\
\hline & & & & 17 & 3 & 3 & - \\
\hline
\end{tabular}

placed in a vaseline well filled with distilled water to which several crystals of Lucifer yellow (LY) had been added. Using a 9-V transistor battery, current was passed between thin silver wire electrodes placed in the LY well and in the protocerebrum. Current was passed for 2-10 $\min$.

The brains were then placed in fixative solution consisting of $4.0 \%$ formaldehyde in $0.2 \mathrm{M}$ phosphate buffer, $\mathrm{pH} 7.4$, for $1 \mathrm{hr}$ to $2 \mathrm{~d}$, dehydrated through a graded series of ethanols, washed in acetone, and embedded in Spurr's plastic medium.

Material was sectioned at $25 \mu \mathrm{m}$ on a sliding microtome and observed under a Lcitz fluorescence microscope. The number of preparations at each stage was: early stage $4, n=2$; midstage $4, n=4$; late stage $4, n$ $=3$; early stage $5, n=2$; stage $5, n=8$; early to midstage $6, n=1$; stage $6, n=4 ;$ stage $13-14, n=1$; stage $14, n=5$.

Golgi impregnations. Following a procedure modified from Strausfeld (personal communication), brains were dissected into Solution A (1.5$2.5 \%$ sodium dichromate with $1.3 \mathrm{gm}$ sucrose $/ 100 \mathrm{ml}$ dichromate), transferred to a $4: 1$ solution of Solution A: $25.0 \%$ glutaraldehyde for 4$8 \mathrm{~d}$, washed with Solution A for $30 \mathrm{~min}$, then transferred to a 1:9 solution of Solution A: $1.0 \% \mathrm{OsO}_{4}$ for 4-8 d, washed in distilled water for 30 min, placed in $0.5 \%$ silver nitrate for $\mathrm{I} \mathrm{d}$, then dehydrated through a graded series of ethanols, and embedded in Epon with dibutyl phthalate (DBP) [Epon $20 \mathrm{gm}$, DDSA $20 \mathrm{gm}$, NMA $8 \mathrm{gm}$, DMP $0.9 \mathrm{gm}$, DBP 9 gm]. Material was sectioned at $60 \mu \mathrm{m}$ on a sliding microtome. The number of uscful preparations at each stage is shown in Table 1.

Fewer successful impregnations were obtained in stage- 5 and younger antennal lobes than in lobes from older animals. Formation of crystals in the young brains was minimized by leaving the brain embedded in the fat and muscle tissue that surrounds it in situ.

Intracellular labeling of antennal-lobe neurons with LY. Brains were removed from the head and placed in a chamber continuously superfused with aerated modified Sattelle's saline. The antennal lobes were desheathed with forceps and a layer of cells underlying the outer perineurial layer was peeled away to reveal the cell-body packets. By stage 5 , the cell-body packets can be distinguished readily from one another. Standard physiological recording and current-passing techniques were used. Electrodes were filled with a $5.0 \%$ solution of LY dye in distilled water. Dye was ejected with 500 msec pulses of 1-2 nA hyperpolarizing current at $1 \mathrm{~Hz}$ for 15-20 min. About $15 \mathrm{~min}$ after completion of an injection, the brain was placed in $4.0 \%$ formaldehyde in $0.2 \mathrm{M}$ phosphate buffer for $1 \mathrm{hr}$ to overnight, rinsed in phosphate buffer, dehydrated through a graded series of ethanols, and stored in methyl salicylate. Brains were mounted in methyl salicylate, photographed, and the cells drawn quickly (15-20 min) with a camera lucida, thus accurately rendering the branching patterns and fiber diameters for branches up to third-order, but only sketchily for higher-order branches. In antennal lobes from which camera lucida drawings were made, only 1 cell was filled in all cases except 1 , which contained 2 cells, one clearly more lightly filled than the other. Some of the brains subsequently were rehydrated to $70 \%$ ethanol, then dehydrated through a graded series of ethanols, washed in acetone and embedded in Spurr's plastic, and then sectioned at $20 \mu \mathrm{m}$ on a sliding microtome.

The number of well-labeled neurons at each stage was: slage 5 normal, $n=6$; stage 5 deantennated, $n=3$; stage 6 normal, $n=7$; stage 6 deantennated, $n=1$; stage 7 normal, $n=14$; stage 8 normal, $n=4$; stage 9 normal, $n=1$; stage 12 normal, $n=1$; stage 12 deantennated, $n=2$.

\section{Results}

Mature neurons from normally afferented antennal lobes have a distinctive pattern of arborization that is reflected in the characteristic glomerular histology of the lobe. This pattern, in which each branch of a neuron forms a spatially discrete, roughly spheroidal arbor (Fig. $1 A$ ), is sharply contrasted by the pattern of arborization seen in neurons from chronically deantennated lobes. Antennal-lobe neurons from deantennated lobes almost always have more homogeneous arbors (Fig. $1 B$ ) that extend to the thick rind of glial cells that envelops the neuropil in these lobcs. In histological sections of deantennated lobes (not shown), the fine-textured neuropil is never seen to become glomerular, forming instead a ring of neuropil around a central region of coarse criss-crossing neurites (Hildebrand et al., 1979; Oland and Tolbert, 1987). The ring occasionally takes on a slightly lobular appearance, a condition mirroring the variation, from totally diffuse to slightly lobular arborizations, seen in Golgi impregnations of antennal-lobe neurons in deantennated lobes (not shown).

\section{Development of antennal axons in the lobe}

As a first step in determining how the various elements that compose a mature glomerulus come together developmentally, we filled antennal nerves with LY at various stages spanning the period of ingrowth of antennal afferent axons (Fig. 2). Axons from receptors whose cell bodies lie in the antenna provide the overwhelming majority of sensory input to the antennal lobe (Sanes and Hildebrand, 1976; Camazine and Hildebrand, 1979; Kent, 1985). At stage 4 (Fig. 2A), antennal axons have just begun to reach the lobe and form a thin partial rim around the outside of the antennal-lobe neuropil. By early stage 5 (Fig. $2 B$ ), the neuropil is completely encircled, and by late stage 5 (Fig. 2C) the axons have formed into small $(30-40 \mu \mathrm{m})$, but distinct spheroidal knots, or "protoglomeruli." During this period, the antennal-lobe neuropil begins to segregate into an outer fine-textured region and a coarse central region, the boundaries of which are indicated in Figure 2 by the arrow heads. The region of finetextured neuropil, which is composed of the neurites of antennal-lobe neurons (see below), is thus surrounded by and distinct from the region occupied by the protoglomeruli. During late stage 5 and into stage 6 (e.g., Fig. 2, C, D), additional ingrowing afferent axons enlarge the original protoglomeruli. In older lobes (e.g., Fig. $2 E$ ), the outer portion of a glomerulus develops a distinctive tulip pattern.

Golgi impregnations of individual afferent axons at stages 5 or 6 (Fig. 3) show sparse terminal arbors within the protoglomer- 

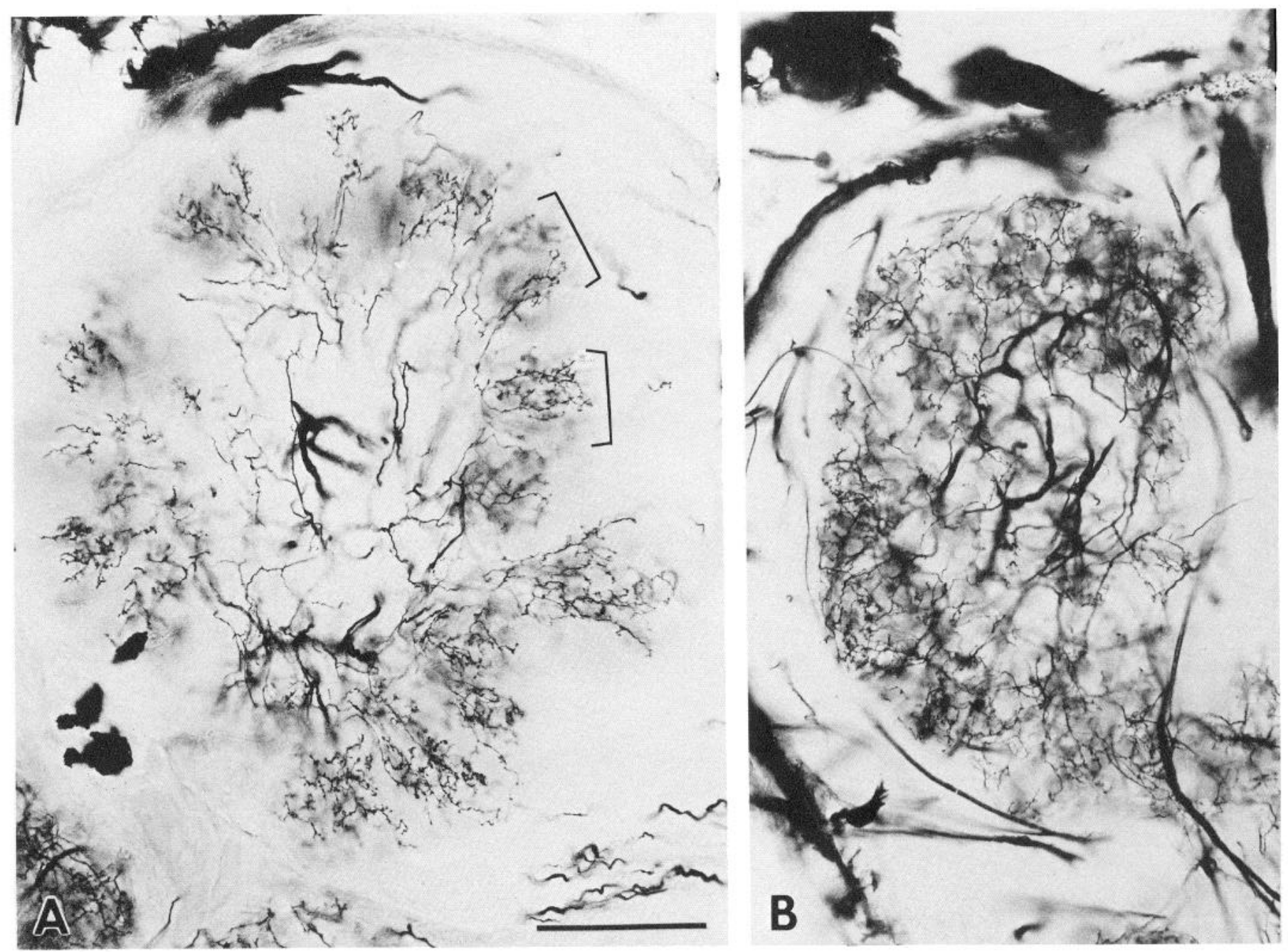

Figure 1. Golgi impregnations of neurons from antennal lobes that would have the appearance of mature lobes in histological sections. $A$, Local interneuron in a stage-14 normally afferented lobe showing prominent glomerular tufting (brackets) of the distal branches and thick branches in the central coarse neuropil. $B$, Neurons from a stage- 12 chronically deantennated lobe showing absence of tufting but similar pattern of central coarse branches and distal fine branches. Outer edge formed by neurites is relatively smooth. Scale bar, $100 \mu \mathrm{m}$.

uli. As yet, we have seen no examples of individual axons branching to innervate 2 or more glomeruli. Even at later stages, including through stage 17 , the terminal arbors of antennal axons remain relatively small with few branches (not shown). No single axon ramifies throughout the territory of the glomerulus. Thus, the terminal arborizations of afferent axons do not individually form dense knots; rather, fascicles of axons that arborize in the same region in space contribute to each protoglomerulus and later to each glomerulus.

\section{Development of local interneurons}

To follow the morphological development of antennal-lobe neurons, we examined Golgi impregnations of neuronal assemblies or of individual antennal-lobe neurons, as well as antennal-lobe neurons labeled intracellularly with LY. Antennal-lobe neurons are classified broadly as local interneurons with arbors confined to the lobe and projection neurons with axons that terminate in higher-order centers in the protocerebrum (Matsumoto and Hildebrand, 1981). At stage 4, when the population of firstarriving afferent axons is beginning to circumnavigate the lobe neuropil, the processes of antennal-lobe neurons fill the entire neuropil out to the glial border (Fig. 4A). At midstage 5, the major neurites of local interneurons occupy the central core and the fine processes remain confined to the middle ring beneath the axon layer (Fig. $4 B$ ). By late stage 5 , there are 3 clear layers of neuropil: the central core of coarse processes, a fine-textured middle ring, and an outer layer of protoglomeruli. Impregnations from stage-6 lobes (Fig. 4C) clearly show this layering and show fine tendrils of the interneurons just beginning to enter the bases of the protoglomeruli.

To correlate the morphologies of individual neurons with the neuritic patterning seen in Golgi preparations, neurons were examined after filling with LY. The structure of an interneuron from a stage- 5 antennal lobe is shown in Figure $5 \mathrm{~A}$. At this stage, many of the neurons examined had long, spiky distal branches reminiscent of filopodia, as well as short tendrils emanating from the thicker secondary and tertiary neurites. The youngest interneurons tended to have extremely fine branches that were often beaded with varicosities and showed no sign of glomerular organization. Sections of stage- 5 lobes, however, revealed that the higher-order branches of these neurons remained 

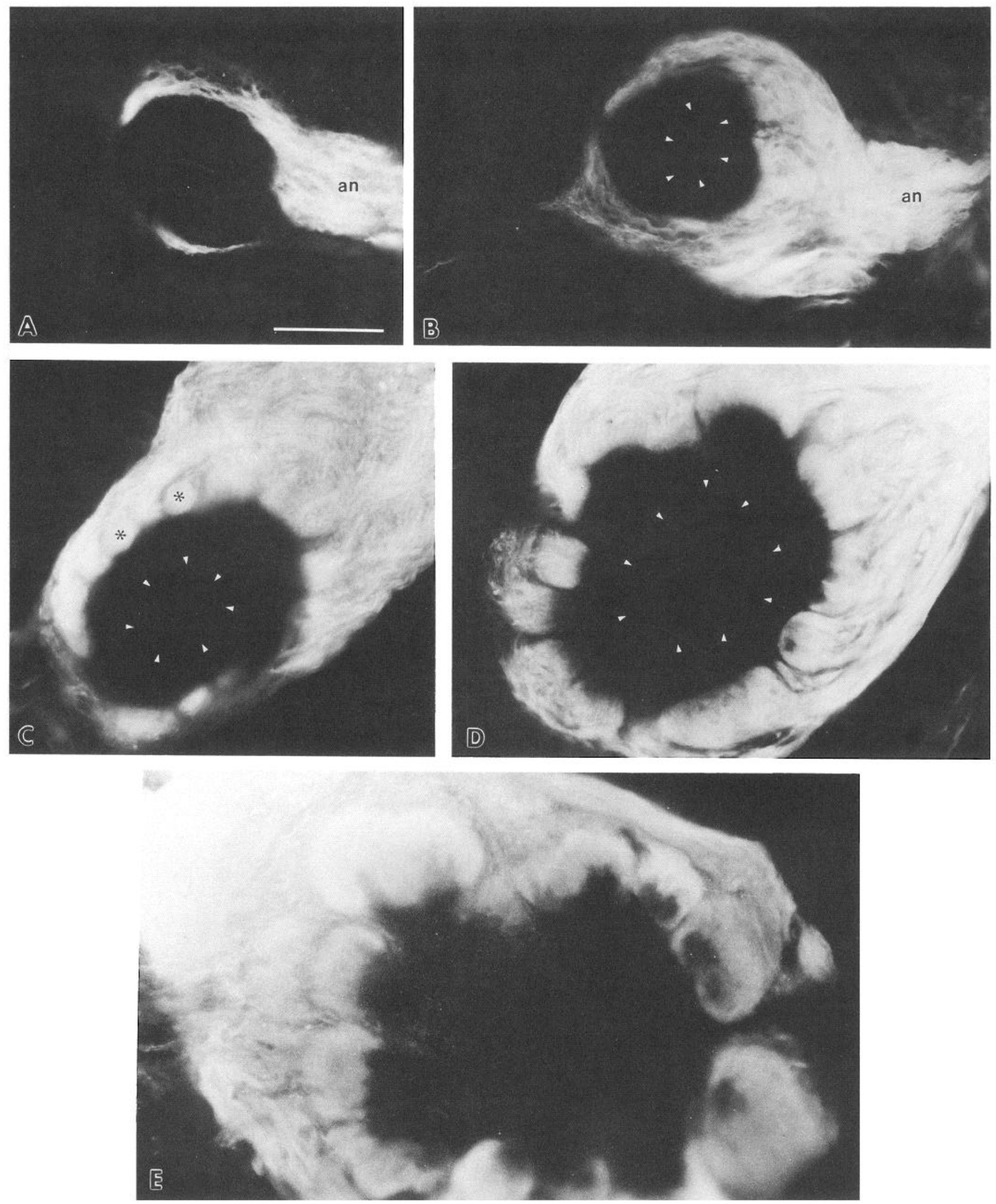

Figure 2. LY-labeled afferent axons of antennal nerves at successive stages of ingrowth into the antennal lobe shown in $25-\mu \mathrm{m}$ plastic sections. $A$, Midstage 4, axons begin to encircle the antennal-lobe neuropil. $B$, Early stage 5 , neuropil completely encircled; arrowheads indicate borders of emerging coarse central neuropil as determined from brightfield photographs of the same section. $C$, Mid- to late stage 5, afferent axons form spheroidal knots, the protoglomeruli $(*) . D$, Stage 6, newly emerging glomeruli. $E$, Stage 14, mature glomeruli; some of the afferent axons extend to the bases of the glomeruli and the coarse neuropil almost fills the unlabeled central region. an, Antennal nerve. Scale bar, $100 \mu \mathrm{m}$. 

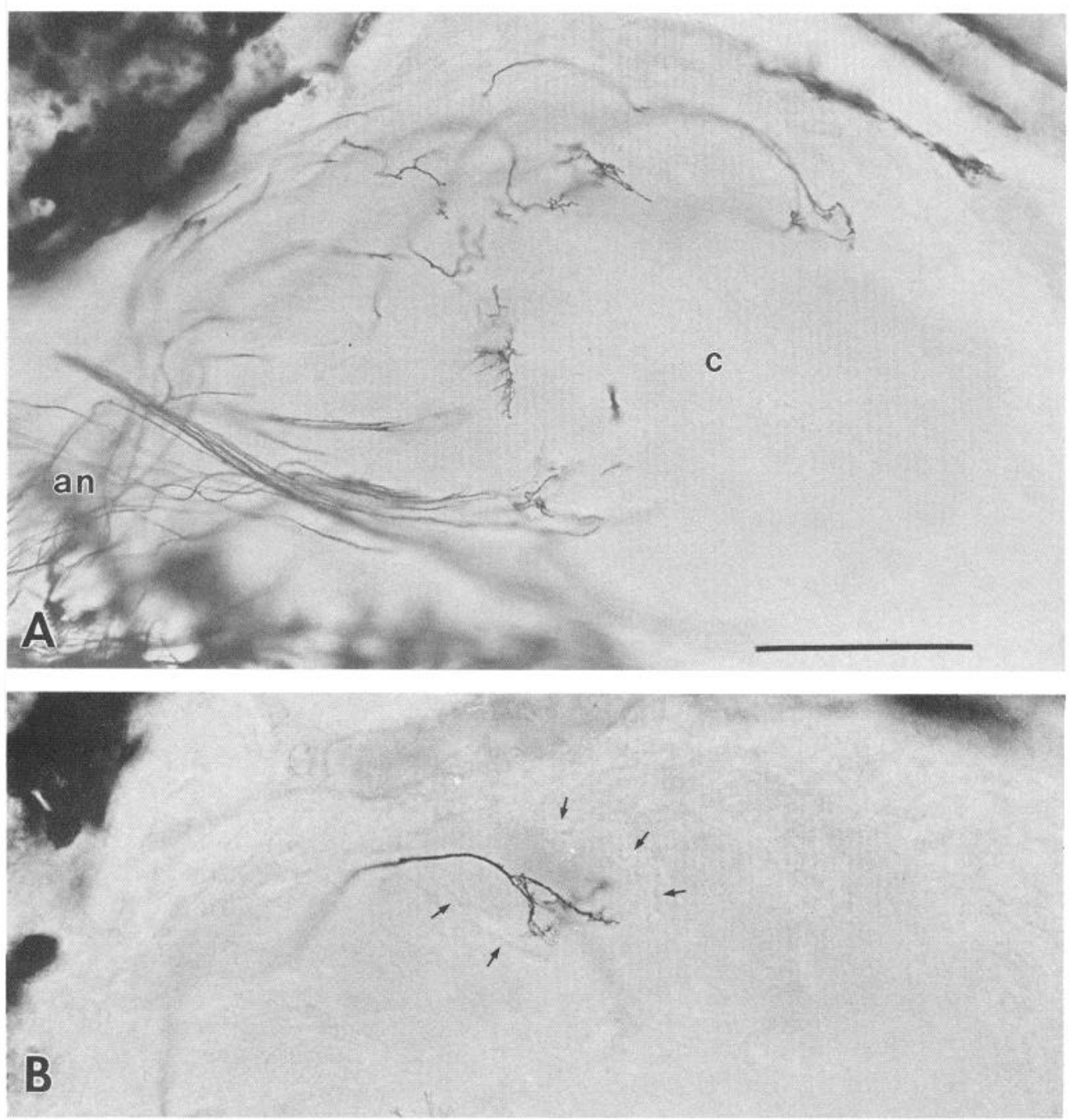

Figure 3. Antennal afferent axons entering the antennal lobe at early stage 6 , stained by the Golgi method. $A$, Terminal arbors of several axons, all branching in the outer region of the neuropil. Lower left shows prominent criss-crossing of afferent axons that occurs in the most proximal portion of the antennal nerve (an). c, Coarse neuropil at center of lobe. $B$, Single afferent axon branching within the body of a protoglomerulus. Glial border (arrows) of this and adjacent protoglomeruli visible as pale processes and cell bodies. Scale bar, $100 \mu \mathrm{m}$ in $A$ and $60 \mu \mathrm{m}$ in $B$. within the middle ring of neuropil (not shown). Not until stage 6 were individual interneurons seen to begin to invade the protoglomeruli.

In each of the 4 whole-mounted stage- 6 preparations in which the faint outlines of the protoglomeruli could be discerned, the distalmost branches of the filled interneuron could be found in the innermost third of the protoglomerulus. When a stage-7 antennal lobe containing a filled interneuron was sectioned, the terminal branches of the neuron were seen clearly to have grown partially into the body of the protoglomerulus (Fig. $5 B$ ). In a series of camera lucida drawings, Figure 6 shows the gradual progression of neurites from local interneurons into the bodies of the protoglomeruli and the gradual sculpting of glomerular arbors. By stage 7, although there is certainly considerable variability in the degree of glomerular tufting among types of interneurons, just as there is in the fully mature antennal lobe (Matsumoto and Hildebrand, 1981; Oland and Tolbert, unpublished observations), each of the branches has acquired a recognizably glomerular shape.

When local interneurons develop in the absence of antennal input, they do not follow the same pattern of morphological development as in control lobes. Figure 7 shows interneurons from deantennated antennal lobes at stages 5-8. In contrast to the rapid change from spiky terminal branches to graceful branching patterns seen in normally afferented cells, these neurons may remain spiky and instantly recognizable as being from a deantennated lobe at least as late as stage 8 (Fig. 7E). A tendency to retain fine processes on the large secondary and tertiary neurites may persist into adulthood, as described above.

\section{Development of projection neurons}

Projection neurons may follow a slightly different pattern of development from local interneurons even in normally afferented lobes. As described in previous work in the mature antennal lobe (Matsumoto and Hildebrand, 1981), projection neurons may be found in all 3 groups of neuronal cell bodies in the lobe. To date, evidence from intracellular and immunocytochemical labeling suggests that the medial and anterior cell groups contain only uniglomerular projection neurons, while the lateral group contains, in addition to local interneurons, both uni- and multiglomerular projection neurons (Christensen and Hildebrand, 1987a; Homberg et al., 1988; Kanzaki et al., 1989). All 3 groups can be distinguished under the dissecting microscope as early as stage 5. A stage-5 projection neuron destined to become uniglomerular by virtue of its cell body location in the medial packet was filled with LY (Fig. $8 A$ ) and found to have 

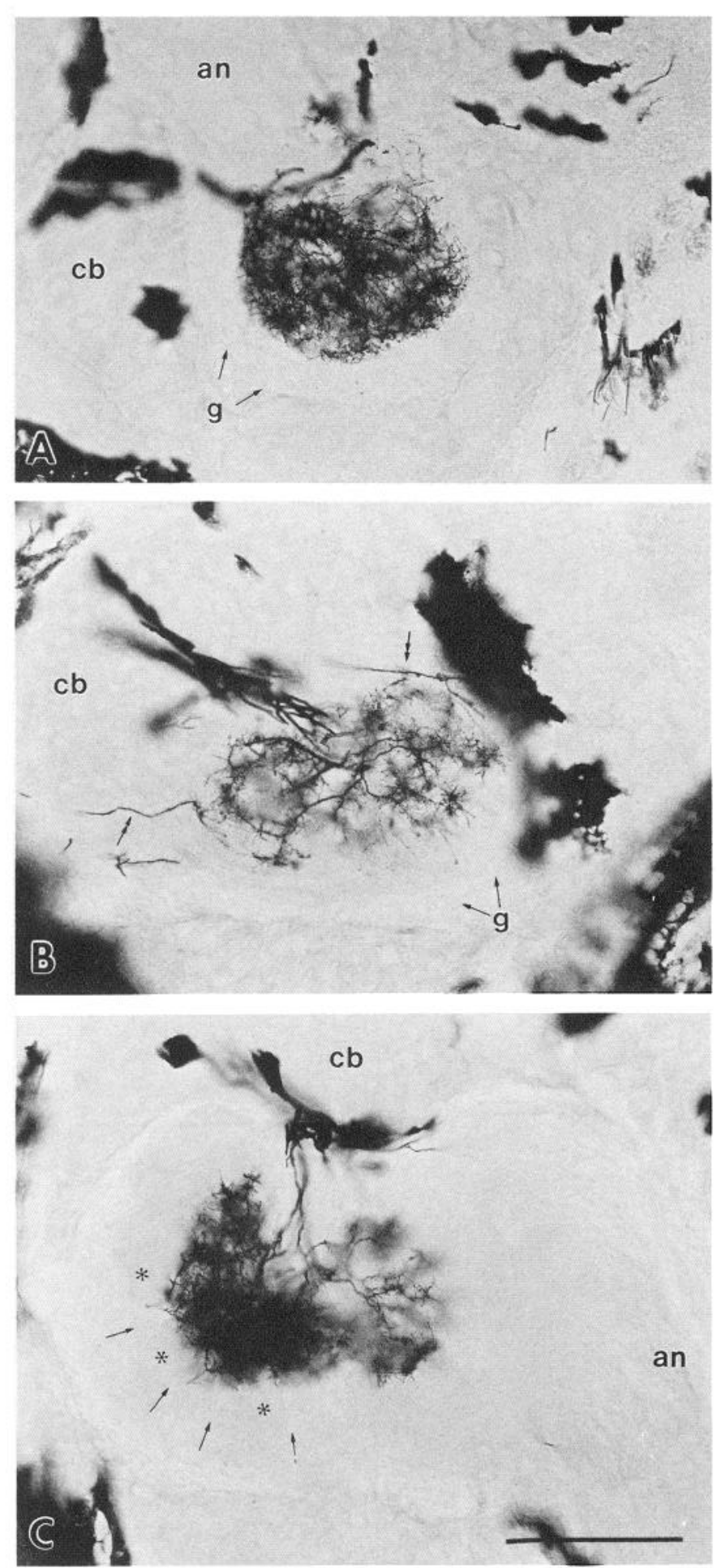

Figure 4. Golgi impregnations of antennal-lobe neurons from young antennal lobes. $A$, Stage 4 , neurites form smooth ball bordered by a rind of neuropil-associated glial cells $(g)$. B. Stage 5 , several neurons whose distal branches are now separated from the glial border by a rim of neuropil formed by the ingrowing afferent axons, several of which also have been stained (double-headed arrows). C, Stage 6, several antennallobe neurons whose distal processes are still predominantly confined to the middle ring of neuropil. Protoglomeruli (*) form an outer layer and are separated from each other by glial septa (arrows). an, Antennal nerve; $c b$, cell bodies of antennal-lobe neurons, several of which are stained. Scale bar, $100 \mu \mathrm{m}$. an arbor restricted to a small, but not glomerulus-sized, region of the neuropil. On the other hand, a stage- 5 projection neuron likely to become multiglomerular showed no evidence of restricted tufting (Fig. $8 B$ ). Figure 9 shows uniglomerular projection neurons of different stages. The Golgi preparation shown in the first panel of Figure 9 indicates that some projection neurons may have glomerular branching patterns even as early as stage 6 . In this preparation, the arbor of an immature, but clearly uniglomerular, neuron fills the body of a protoglomerulus and even extends a few isolated branches into the surrounding glial border. To date, as mentioned above, we have not seen glomerular tufting at this stage in any local interneuron; in fact, neurites of interneurons at this stage are only just beginning to penetrate into the bases of the protoglomeruli. Camera lucida drawings of stage- $6,-7$, and -8 neurons labeled intracellularly reveal well-developed uniglomerular projection neurons (Fig. 9). In all cases, their axons extended to typical sites in the protocerebrum and formed terminal arbors with varicose branches.

Projection neurons developing in the absence of antennal input vary in the degree to which their arbors develop. The stage12 LY-filled projection neuron shown in Figure 10 had a restricted, but not glomerulus-sized, arbor, remarkably similar to that of the young (stage-5) normal projection neuron shown in Figure $8 \mathrm{~A}$. On the other hand, an arbor that closely resembled a uniglomerular arbor in size and branching pattern appeared in one Golgi preparation of a stage- 8 deantennated antennal lobe (not shown).

All cells labeled with LY, whether in normal or deantennated antennal lobes, showed synaptic activity. Moreover, of 27 stage- 5 neurons impaled, 2 projection neurons from the anterior group of neurons in normal antennal lobes were capable of generating spontaneous action potentials. No attempt was made, however, to study in detail the physiological behavior of young antennal-lobe neurons prior to iontophoresis of LY because all impalements were made in the cell body and the resting membrane potentials were low $(-10$ to $-30 \mathrm{mV})$.

\section{Development of synapses}

Given the pattern of growth of the processes of antennal-lobe neurons into the protoglomeruli, we were interested to know the temporal and spatial distribution of synapses in the developing glomeruli. For this purpose, montages were constructed at a magnification of $20,250 \times$ from electron micrographs of the antennal-lobe neuropil during stage 6 (early, middle, and late), when protoglomeruli lie adjacent to the middle ring of neuropil and are first invaded by the processes of antennal-lobe neurons; at stages 7 and 8, during initial growth of the newly formed glomeruli and at stage 12, when glomeruli appear histologically mature and synaptic density has plateaued at its adult value (Tolbert et al., 1983). In Figure 11, the position of processes forming the glial border of the chosen protoglomeruli (early and late stage 6) or glomerulus (stage 12), the positions of synapses, and the location of the edge of the middle ring or the coarse central neuropil are indicated. "Definite" synapses are shown in order to give the most conservative view of the spatial distribution of synapses at each stage. "Probable" synapses (less stringent criteria as defined in Materials and Methods) are included, and separately coded, to reveal the maximum possible distribution of synapses.

These montages show that at early stage 6 , the protoglomerulus identified at the light microscopic level as a knot of finetextured neuropil consists predominantly of a tangle of small 

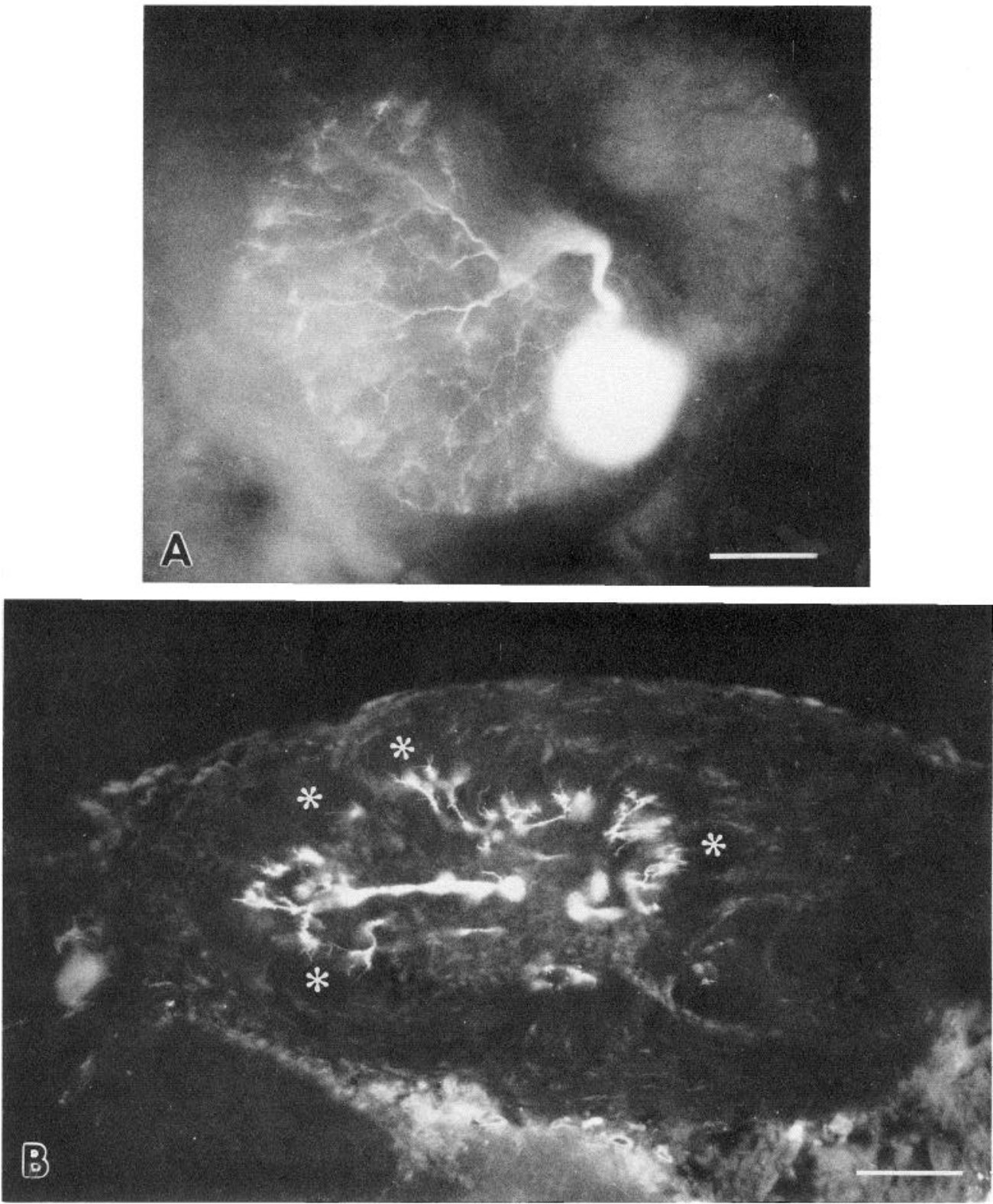

Figure 5. Antennal-lobe interneurons labeled intracellularly with LY. $A$, Stage-5 interneuron whose cell body lies in lateral group; branches ramify throughout the neuropil. Note that the cell body, which is out of the plane of focus in this wholemount, appears larger than actual size because of the halo effect. $B, 20-\mu \mathrm{m}$ section through a stage-7 antennal lobe containing a labeled interneuron. Processes of the neuron have invaded the protoglomeruli to form glomeruli, several of which are indicated with ${ }^{*}$. Scale bars, $100 \mu \mathrm{m}$. fascicles of afferent axons, some of which can be traced to the afferent axon layer surrounding the neuropil. A wall of glial processes surrounds the outer edge and sides of each protoglomerulus. Many of the neuritic processes are filled with irregular membranous sacs, suggesting that they are growth cones. Particularly toward the outer edges of the protoglomerulus, many of the neuritic profiles are almost entirely filled with vesicles, although we saw no evidence of other synaptic specializations here. In the 3 early stage- 6 protoglomeruli we examined, we found synapses only near the base of the protoglomerulus. On the other hand, many neuritic profiles participate in symmetrical junctions, and numerous focal membrane specializations (Tolbert et al., 1983; Tolbert, 1989) between 2 or more adjacent profiles are scattered throughout the protoglomerular neuropil. Neurites contained in the middle ring of neuropil that lies beneath the protoglomeruli tend to be more heterogeneous in size, with both thick and fine processes intertwined, and they make numerous synapses.
In successive stages, the distribution of synapses gradually expands further and further outward into the developing glomeruli. By stage 8 , synapses are scattered almost throughout the glomerular neuropil. By stage 12, most synapses are located on small processes (also reported by Tolbert, 1989). In Figure 11, "probable" synapses are indicated by dotted circles. The frequency of these synapses at each stage tends to be greatest at the outer edges of the developing synaptic region, suggesting that many of the "probable" synapses are actually developing synapses.

Consistent with our previous observations with the light microscope (Oland and Tolbert, 1987), glial processes gradually extend toward the central region of the antennal-lobe neuropil, forming walls that bound glomeruli. These walls are composed initially of many thick glial processes and occasionally include widened, membrane-filled profiles that could be glial growth cones (not shown). By stage 12, the interglomerular glial walls have thinned as their constituent glial processes have thinned, 

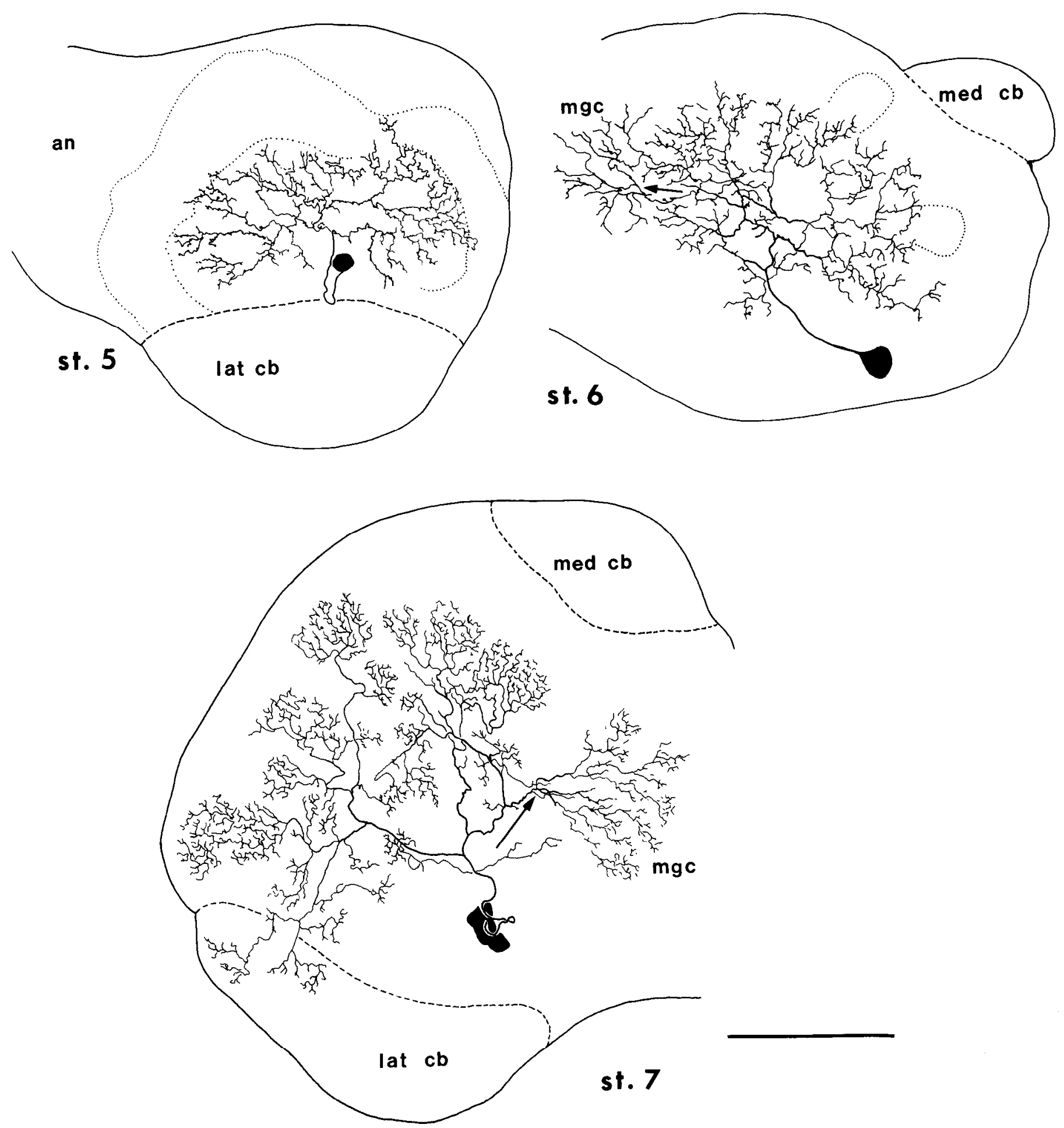

Figure 6. Camera lucida drawings of local interneurons labeled intracellularly with LY and viewed in wholemount showing patterns of arborization common at each stage. Borders of the protoglomerular layer (stage 5) or some of the newly developing glomeruli (stage 6) are indicated by dotted lines. The stage- 6 and -7 neurons each had a branch (arrows) in the male-specific macroglomerular complex ( $m g c$ ). Cell bodies of the neurons labeled at stages 5 and 6 lay in the lateral group; the position of the stage- 7 neuron's cell body was unclear and could have belonged to either the anterior or lateral group. an, Antennal nerve. Scale bar, $100 \mu \mathrm{m}$.

and the basal interstices among glomeruli have come to include aggregations of glial cell bodies. Glial processes also have infiltrated the coarse neuropil and have come to surround, either singly or in small groups, the large neuritic processes that compose the central region (as also noted by Tolbert, 1989). With the exception noted below, glial processes are found only rarely within the glomerular neuropil so that, at the electron microscope level, the base of a glomerulus is seen as a sharp border between a region of large, glia-surrounded neurites and one of a tangle of fine processes virtually lacking glia (Fig. 11C). 

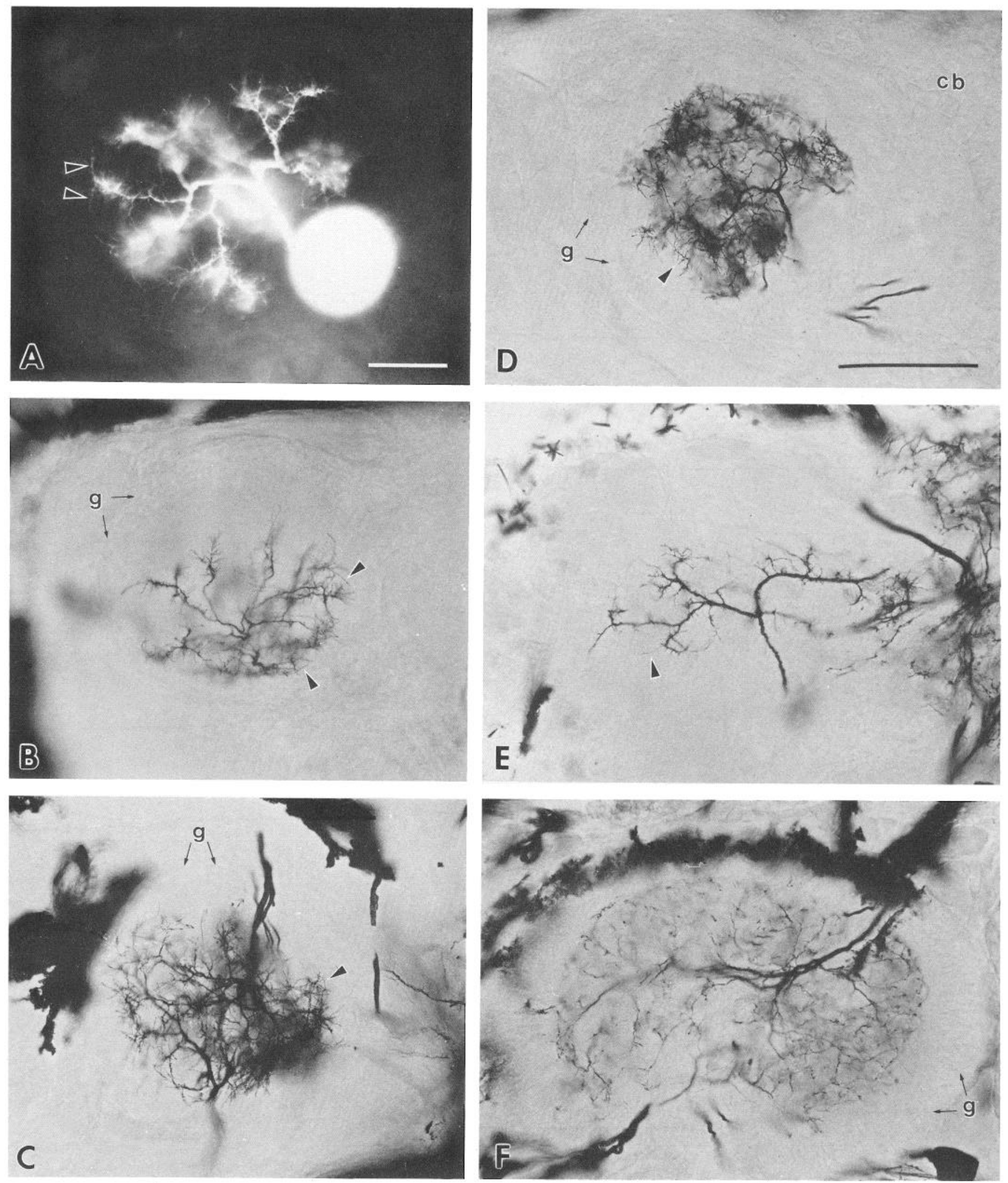

Figure 7. Antennal-lobe neurons from chronically deantennated lobes at different developmental stages. $A$, Stage-5 neuron labeled intracellularly with LY and viewed in wholemount. Distal branches typically bear long spiky processes (arrowheads) and small, wispy tendrils appear on thicker processes. The cell body is out of the plane of focus. Scale bar, $100 \mu \mathrm{m}$ and applies only to $A$. $B$ and $C$, Sections through Golgi-impregnated neurons in stage-5 antennal lobes, one $(B)$ showing a typical morphology in which branches are studded with coarse spikes and the other $(C)$ showing a morphology that approaches that of neurons in normally afferented lobes. $D$, Stage $6 . E$ and $F$, Stage-8 neurons showing variability in branching patterns, some neurons as in $E$ retaining the spiky branching pattern (arrowhead) seen antennal-lobe neurons from younger normally afferented lobes, while others as in $F$ generally resembling normal neurons except for the absence of glomerular tufting. Note thick glial border, $g$. $c b$, Cell bodies of antennal-lobe neurons. Scale bar in $D$ for $B-F, 100 \mu \mathrm{m}$. 

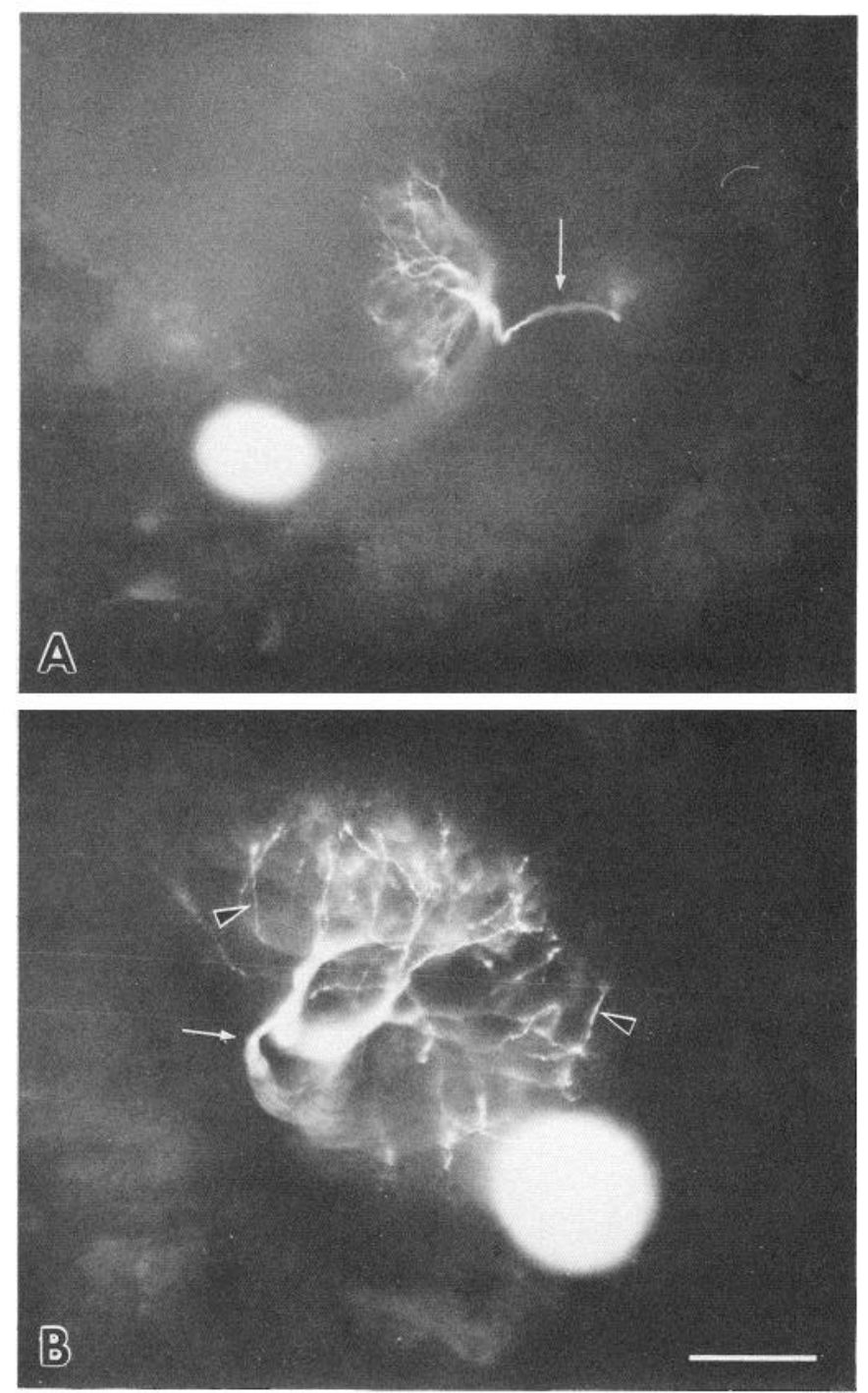

Figure 8. Stage-5 antennal-lobe projection neurons intracellularly labeled with LY and viewed in wholemount. $A$, A presumptive uniglomerular projection neuron, whose cell body lies in the medial group of antennal-lobe neurons, showing that its basic branching pattern is already in place. $B, A$ presumptive multiglomerular projection neuron whose cell body lies in the lateral group and whose branches arborize throughout much, if not all, of the neuropil. Arrowheads indicate long spiky branches typical of this stage. Arrows, axons. Scale bar, $100 \mu \mathrm{m}$.

We have found that glial processes, identified by the presence of glycogen and ribosomal particles, do sometimes appear within the fine-textured neuropil of the glomerulus. In Figure $11 C$, the majority of intraglomerular glial processes are associated with fascicles of afferent axons penetrating the glomerulus from its outer border.

While preparing the montages, we also looked at high power in the electron microscope for evidence of specialized junctions between neurons and glial cells that could serve as the substrate for passage of signals from afferent axons. For stages 3-7 we generated montages at a magnification of $27,000 \times$ of long (approximately $1 / 8$ of the circumference) regions of the glial border where it is contacted by ingrowing antennal axons. Despite extensive searching, we detected only a few specialized junctions involving glial cells at these stages. Scalariform-like junctions (Fig. 12B) between glial cells were fairly common at stage 4 and at stage 7 and thereafter. Junctions similar to desmosomes could be found between glial-cell pairs (Fig. 12A) and neuron-glia pairs (Fig. 12C) at all stages. Two additional types of junctions were seen, but only rarely, between neurons and glia: (1) punctate regions of close apposition that might represent tight junctions (Fig. 12D) and (2) regions of rigidly parallel membranes separated by a widened intracellular space that was filled with flocculent material (Fig. 12E). The latter type are similar to the specializations observed by Gregory et al. (1988) between cultured cerebellar granule cells and the radial glial cells along which they are migrating.

\section{Discussion}

This study was designed to explore the cellular interactions that occur during the stages in which glomeruli are forged from an unremarkable, homogeneously textured neuropil. We have followed the ingrowth of antennal axons, the formation of protoglomeruli surrounded by glial cells, the invasion of protoglomeruli by neurites of antennal-lobe neurons, the development of glomerular arbors in different classes of antennal-lobe neurons, and the formation of synapses in the developing glomeruli. We have also followed the development of neuritic arbors in the absence of antennal afferent axons. Our results indicate that antennal afferent axons, and possibly some of the uniglomerular projection neurons of the antennal lobe, form an array of structures we term "protoglomeruli" that serves as a template for the development of adult glomeruli.

\section{Formation of the protoglomeruli}

Antennal axons begin to arrive in the lobe early in stage 4 (Kent, 1985; Oland and Tolbert, 1987) and gradually encircle the neuropil containing the neurites of antennal-lobe neurons. Fascicles of axons dive through the glial border under which they form a thin layer. At stage 5, glial cells begin to extend processes toward the center of the neuropil and the layer of afferent axons thickens and coalesces into spheroidal knots, or protoglomeruli, each becoming surrounded by glial processes and cell bodies during stage 6.

Formation of the protoglomeruli in Manduca appears to be an intrinsic capability of aggregates of primary olfactory axons. This ability has been observed previously in moths (Sanes et al., 1976; Kent, 1985; A. M. Schneiderman and J. G. Hildebrand, unpublished observations) and in rodents (Graziadei et al., 1979; Graziadei and Samanen, 1980) in which either the brain has been removed or the axons have been forced to grow into ectopic regions of the CNS. The protoglomerular neuropil of the developing antennal lobe appears to consist primarily of fine branches of afferent axons; the neurites of most antennallobe neurons are confined until about midstage 6 to the middle ring and newly emerging coarse neuropil. The shape of the protoglomeruli does not reflect the branching pattern of single axons, for their meager terminal arbors do not themselves describe a spheroidal shape; rather, the protoglomerulus is produced by the branching of multiple axons in register. Furthermore, the simple, sparsely branched arbors that appear at stages 5 and 6 persist into adulthood with little expansion, so that the terminal field of a single antennal axon continues to occupy only a small portion of the territory of a glomerulus.

One Golgi preparation of an early stage- 6 projection neuron (Fig. 9) suggests the possibility that while the terminal branches of afferent axons clearly constitute the preponderant neuronal element in the protoglomeruli, a class of early developing pro- 


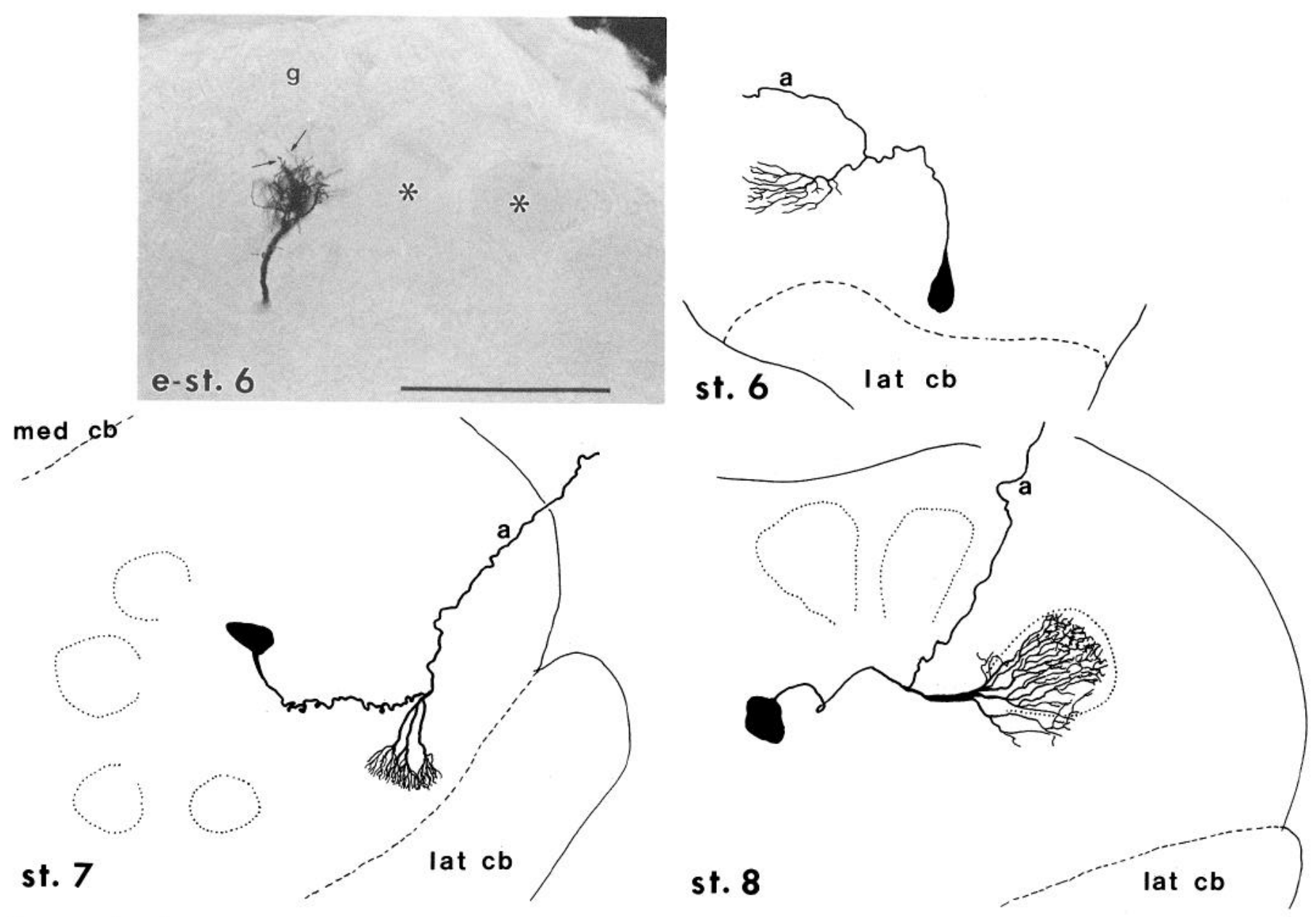

Figure 9. Typical patterns of arborization in uniglomerular projection neurons at successive developmental stages. $60-\mu \mathrm{m}$ section through an early stage-6 Golgi-impregnated neuron (upper left) shows a clearly restricted arbor possibly branching within a protoglomerulus. Neighboring protoglomeruli are marked with *. Camera lucida drawings of neurons labeled intracellularly with LY are from stage- 6 to -8 lobes and are viewed in wholemount. Dotted lines mark the edges of some of the glomeruli visible in the lobe. Scale bar, $116 \mu \mathrm{m}$ for the photograph and $100 \mu \mathrm{m}$ for the
drawings.

jection neurons also may contribute processes. One would like to know if each protoglomerulus is endowed with one or perhaps more such projection neurons. If so, cells of this class of projection neuron possibly could serve as nucleating centers around which bundles of axons congregate to form protoglomeruli. The mechanism for such an interaction is not likely to be synaptic as we observed no synapses in the protoglomeruli at this stage.

In addition, because nothing is known of the positions, at different stages, of the arbors of any of the small number of centrifugal neurons terminating in the antennal lobe or of the pair of 5-HT immunoreactive cells that are known to be present throughout metamorphic adult development (Kent et al., 1987), the possibility also exists that these cells may play a role in the initial formation or specification of protoglomeruli.

The scenario described for Manduca has similarities and some differences with the sequence of events in rats and mice (MontiGraziadei et al., 1980; Brunjes and Frazier, 1986; Farbman, 1986), where olfactory sensory axons, which actually induce the formation of the olfactory bulb, grow in from the periphery to encircle the developing bulb during embryogenesis. At birth, glomeruli are still ill defined; even when afferent axons are stained for olfactory marker protein, only a few "glomeruli" are seen, suggesting that if the axons form a protoglomerular template for glomeruli, it is not at this time. (However, in the absence of normal target tissue, the olfactory axons do form protoglomerulus-like structures as described above.) The glomeruli gradually become obvious over the next several days as they are surrounded by upwardly migrating cells of the glomerular layer. Interestingly, early in development a small number of sensory axons penetrate deeply into the core of the bulb (Hinds, 1972a, b; Monti-Graziadei et al., 1980) rather than confining their terminal branches to the superficial layer they will occupy in the mature system; these axons are in a position to interact directly with olfactory bulb neurons, which lie deep to the glomerular layer. While we did not observe deeply penetrating axons in the antennal lobe of Manduca, equivalent neuron-neuron interactions could take place in both systems if, in the antennal lobe, a class of projection neurons does arborize in the protoglomeruli (see below). To our knowledge, the question of whether glial cells surround the developing glomeruli in mammals has not been answered, so we cannot yet make comparisons concerning the role of glia.

\section{Morphological differentiation of antennal-lobe neurons}

By using Golgi preparations and intracellular injections with LY, we were able to obtain a broad, if not comprehensive, 


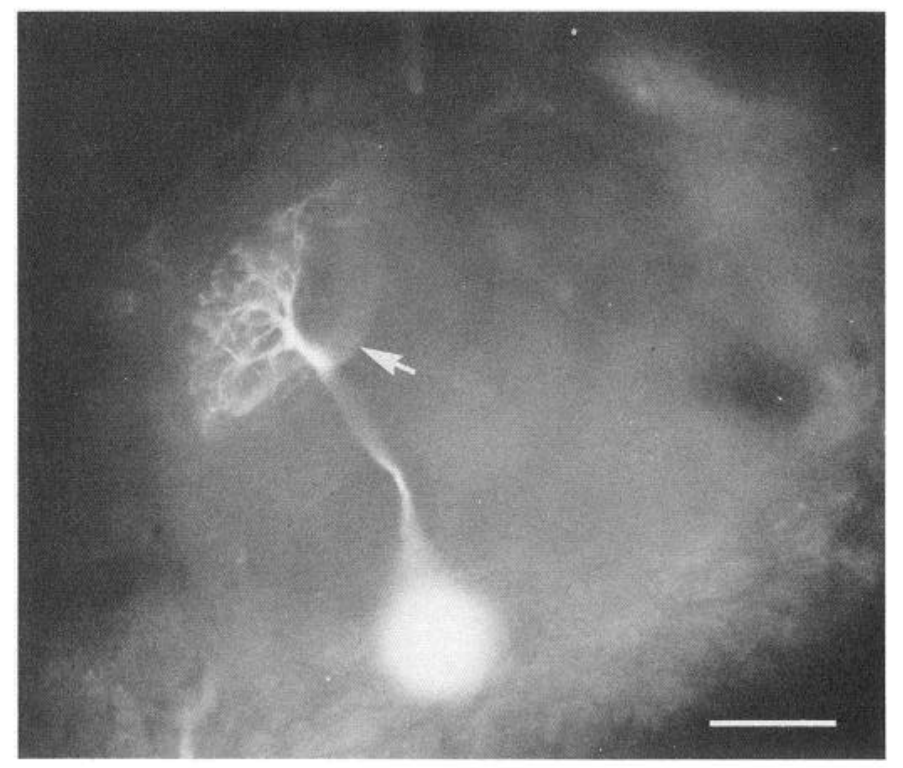

Figure 10. Restricted arbor of projection neuron from chronically deantennated stage-12 antennal lobe, labeled intracellularly with LY and viewed in wholemount. Arrow, axon. Scale bar, $100 \mu \mathrm{m}$.

sampling of local-interneuron and projection-neuron types during the stages in which the neuropil was being partitioned into glomeruli. At stage 5, when the arbors of antennal-lobe neurons apparently do not extend outwardly beyond the middle ring, none of the local interneurons had a glomerular pattern of arborization, and most had extremely fine branches that were very immature in their branching pattern. The arbors of local interneurons gradually become glomerular as they grow into the protoglomeruli. By stage 8 , glomerular tufts have been established, these tufts becoming more elaborately branched through later development. Immature features, such as the presence of tendrils on the large processes, also gradually disappear.

The degree to which any central neuron in the antennal lobe becomes glomerular depends significantly on its class. The Golgi preparations of stage-16/17 antennal lobes revealed that not all local interneurons develop a pronounced glomerular pattern of branching. Some, in fact, branch rather sparsely, but in all cases, it is clear from inspection of whole mounts or sectioned material that all local interneurons have arbors in which the branches ramify within the territory of individual glomeruli.

In many other systems afferent axons are known to influence the development of neuronal morphology (Rakic and Sidman, 1973; Murphey et al., 1975; Hoy et al., 1978; Macagno, 1979; Schildberger et al., 1986; Goodman et al., 1988; Deitch and Rubel, 1989). Several lines of evidence indicate that, while this appears to be true for local interneurons in the antennal lobe, morphological development of projection neurons may proceed largely independently of antennal afferent input. By stage 6 , in contrast to local interneurons, uniglomerular projection neurons already have acquired some of their mature characteristics, such as a distinctly glomerular tuft and an axon projecting to the regions of the protocerebrum typically innervated by antennallobe neurons in the adult (Christensen and Hildebrand, 1987b; Homberg et al., 1988; Kanzaki et al., 1989). In addition, these characteristics appeared in projection neurons in a small number of deantennated antennal lobes, whereas local interneurons retained their immature aglomerular branching patterns in the absence of antennal axons. Moreover, recent experiments in vitro (Hayashi and Hildebrand, 1990) have shown that antennallobe projection neurons in culture develop profiles of current consistent with physiological behavior measured in projection neurons in situ. In contrast, putative local interneurons in culture develop only slowly inactivating, outward currents, suggesting that they require additional cues to differentiate fully.

One reason for the apparent lessened dependence of projection neurons on afferent axons might be that these neurons receive developmental cues from their targets in the protocerebrum. The finding that at stages 5 and 6 the axons of projection neurons have varicosities on their terminal arbors in the protocerebrum suggests that synaptic interaction may already have been established at these early stages.

\section{Synaptogenesis in the developing glomeruli}

Synapses can be found in the antennal-lobe neuropil as early as we have looked during the period of metamorphic development. In previous studies of the development of synapses, Tolbert and colleagues (Tolbert et al., 1983; Tolbert, 1989) identified several types of specialized junctions in the neuropil, including focal contacts characterized by membrane-associated densities in 2 or more adjacent elements, as well as typical synaptic specializations. In the later study (Tolbert, 1989), junctions of all types were found to be distributed throughout the neuropil in the young antennal lobe. Our current results confirm both the types and distribution of specializations present during stages 5-8. Because we have improved the resolution of our study by subdividing stages 5 and 6 , we now know that, from late stage 5 through early stage 6 when protoglomeruli are present, the pattern described by Tolbert holds for the middle ring and coarse central neuropil, but not for the protoglomeruli. In the current study, we observed no synapses in the protoglomeruli until about midstage 6 , when processes of many antennal-lobe neurons begin to invade the basal regions of the protoglomeruli. After this time, the distribution of synaptic profiles in the nascent glomeruli gradually advances distally and the number of synapses increases. Glial processes, meanwhile, continue to grow toward the center of the lobe so that the synaptic neuropil of the middle ring gradually becomes incorporated into the confines of glomeruli by stage 7 .

During the time of this advance, the overall proportion of definite synapses increases, but the ratio of definite to probable synapses is not uniform across the glomerulus. At the advancing edge, the proportion of probable synapses was always greater than the proportion of definite synapses, suggesting that many of these incomplete-appearing synaptic specializations are immature rather simply tangentially sectioned synapses.

Both the LY labeling and the Golgi impregnations of stage-5 and early stage- 6 antennal-lobe local interneurons showed that the territory occupied by their higher-order branches is restricted to the middle ring of neuropil. At these same stages, synapses are also located in the middle and central coarse neuropils. Thus, the synaptic activity that we recorded in young antennallobe neurons must reflect primarily interactions between antennal-lobe neurons. The first synaptic contacts between afferent axons and the majority of second-order cells must occur during or after midstage 6 , when the processes of these antennal-lobe neurons begin to invade the protoglomeruli. Even at stage 8 , many of the synapses in the young glomeruli have an immature appearance ultrastructurally, especially in the outermost portions of the neuropil. These findings may explain the inability 

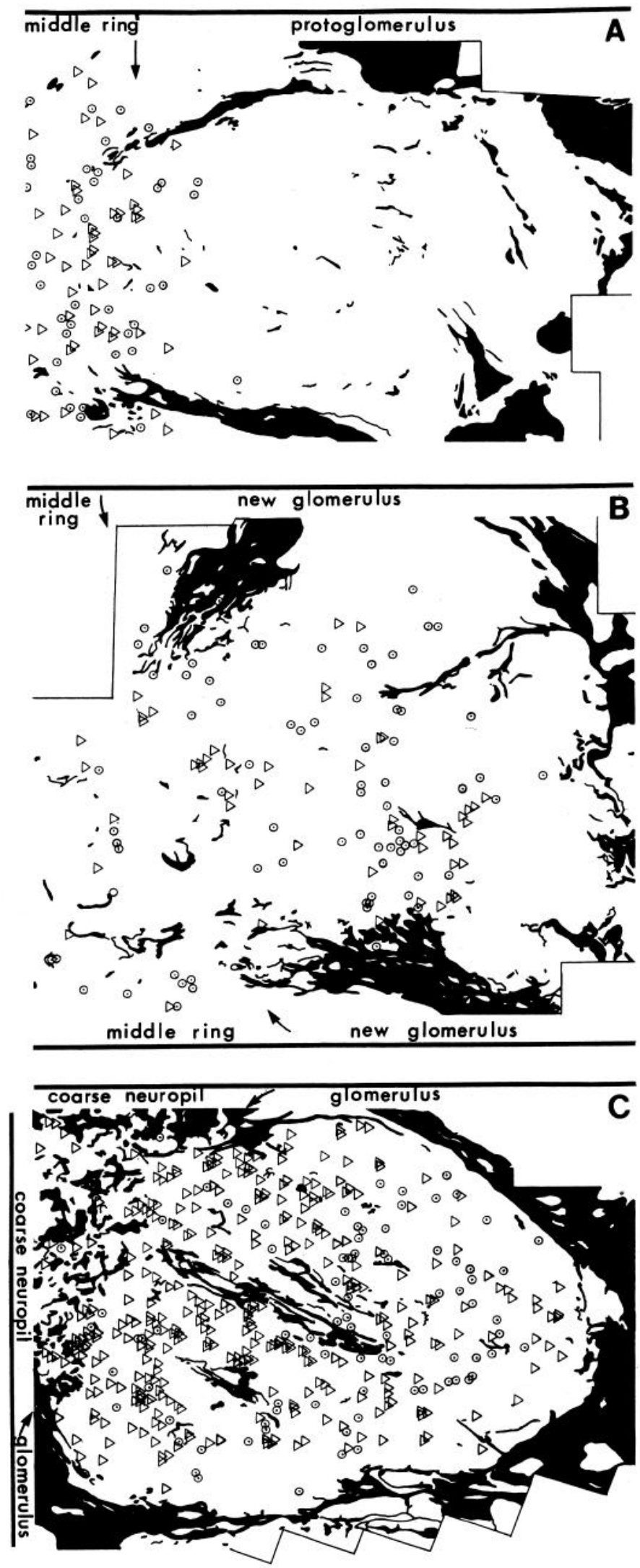

Figure 11. Scale drawings of electron-micrograph montages of a protoglomerulus $(A)$ from an early stage-6 lobe, a newly emerging glomerulus $(B)$ from a late stage-6 lobe, and a glomerulus $(C)$ from a stage12 lobe, showing the position of glial processes (black profiles), "definite" synapses (triangles), and "probable" synapses (open dotted circles) of Tolbert et al. (1983) to detect responses to stimulation of the antennal nerve with current in antennal-lobe neurons before stage 9 .

A delay between ingrowth of afferent axons and the onset of synaptogenesis with targets is apparently a widespread phenomenon in the developing nervous system (Wise and Jones, 1978; Konishi and Akutagawa, 1985; Tosney and Landmesser, 1985; Shatz and Luskin, 1986) and has been observed specifically in the developing mammalian olfactory bulb (Hinds and Hinds, 1976; Farbman, 1986). Reasons suggested for this delay have included mismatched maturities of afferents and their targets (Shatz and Luskin, 1986) and time required for interactions between olfactory axons from scattered regions of the olfactory epithelium (Carr et al., 1989). In the antennal lobe, we suggest that the delay provides time for glial cells to enwrap the protoglomeruli before the majority of antennal-lobe neurites invade. Without glial enwrapment, we know that newly formed glomeruli are not stable (Tolbert and Oland, 1990).

\section{Advances in our understanding of the role played by glial cells in the construction of glomeruli}

In previous papers (Oland and Tolbert, 1987, 1988; Oland et al., 1988; Tolbert and Oland, 1989), we have put forward the hypothesis that antennal afferent axons induce changes in glial cells, which then constrain antennal-lobe neurons to branch in glomerular patterns. In other words, we have proposed that afferent axons exert a morphological effect on their target neurons using glial cells as intermediaries. The more detailed understanding of the morphological development of cells in the lobe gained in the present study, taken together with the previous results, leads us to suggest that the initial steps in the formation of glomeruli depend primarily on an interaction between glial cells and afferent axons, rather than one also involving the majority of target neurons.

The mechanisms by which glial cells interact with afferent axons and subsequently affect the branching patterns of antennal-lobe interneurons and perhaps projection neurons still are not clear. The rarity of specialized contacts observed between glia and neurons in the present study suggests that the passage of signals from axons to glia and from glia to antennal-lobe neurons is not likely to depend on contact (although it could; LoPresti et al., 1974). More likely are changes in the expression of surface molecules or in the release of substances acting at short distances. Evidence from studies in the barrel system of rodents suggests that afferent input may regulate expression of such molecules (Steindler et al., 1989). In addition, glial cells may affect the branching of neurites by forming an envelope that acts as a simple physical constraint on neuritic outgrowth.

Detailed examination of montages of protoglomeruli and glomeruli from several stages showed that glial processes, previously thought to be virtually excluded from glomerular neuropil, may with some regularity be found adjacent to or surrounding bundles of afferent axons in the glomerular neuropil. This consistent association suggests that glial processes may accompany axons growing into the glomeruli. Although no obvious morphological or ultrastructural characteristics distinguish neuropil-

Boundaries of coarse or middle ring of neuropil indicated by arrows at
the edge of each drawing. The distribution of synapses gradually prothe edge of each drawing. The distril
gresses outward to fill the glomeruli. 

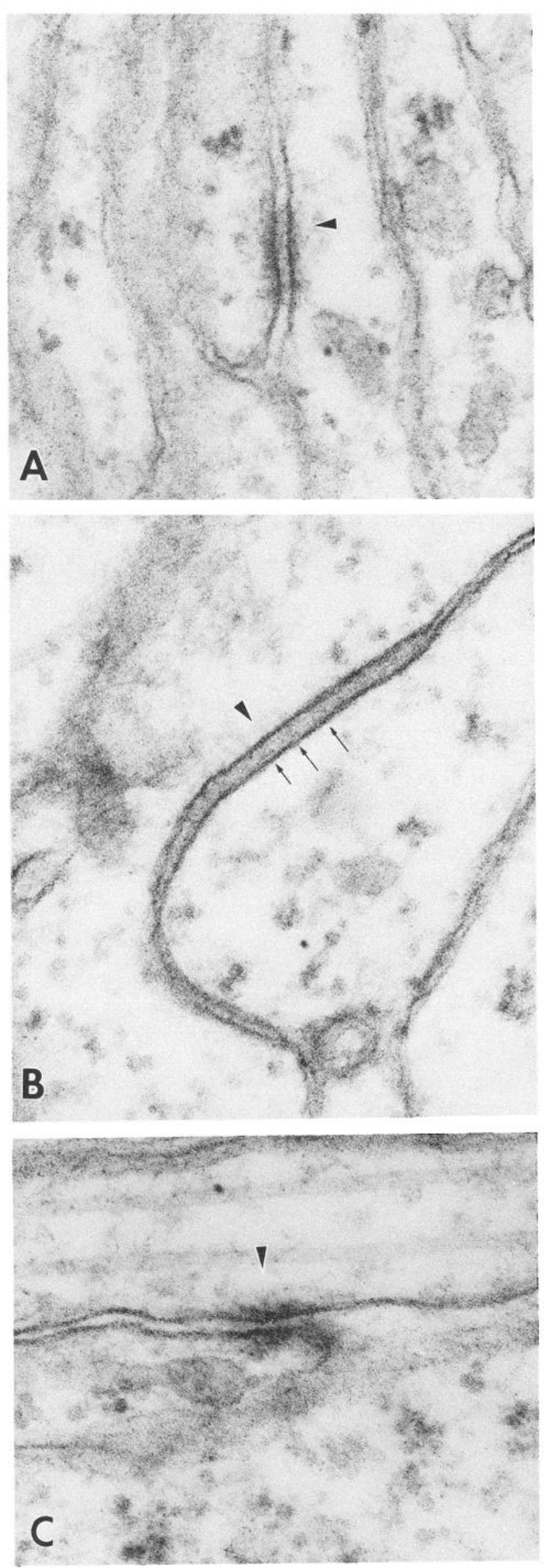

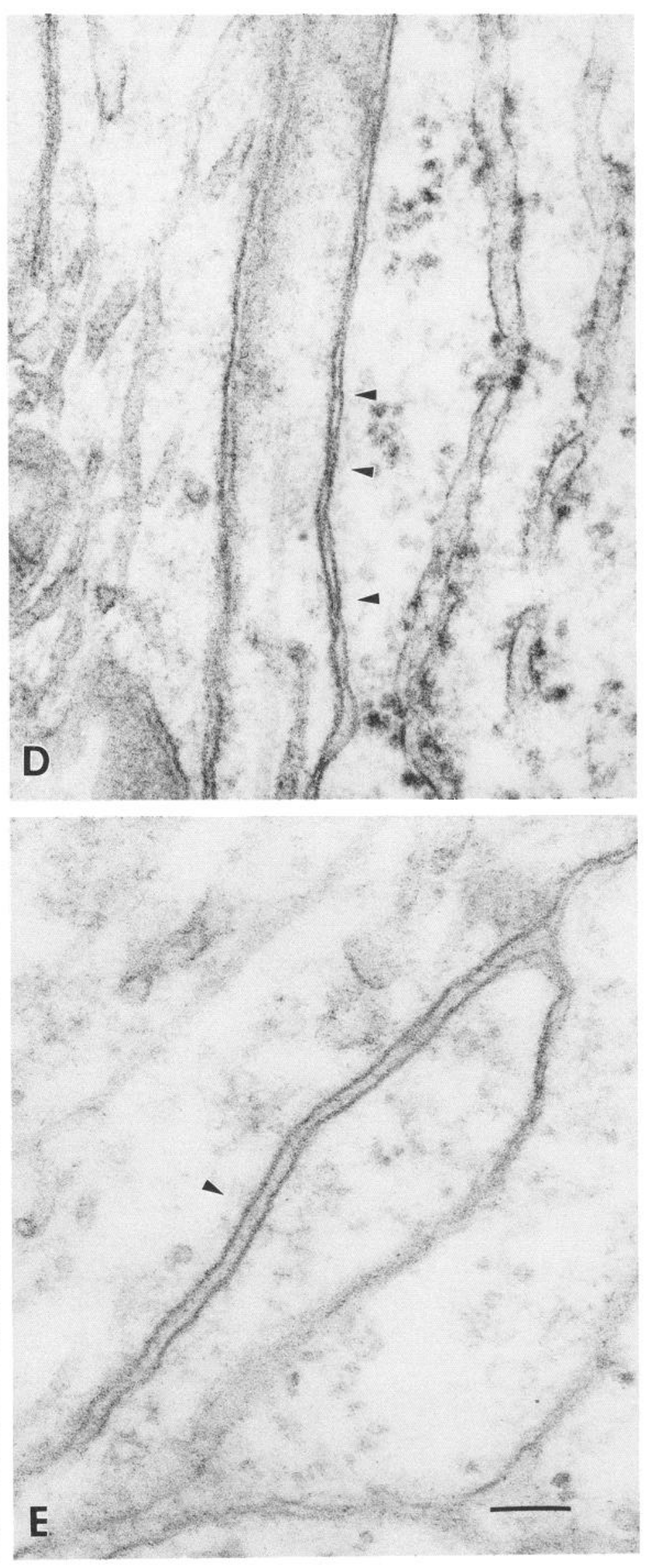


associated glia (Wigglesworth, 1972; type iv) from peripheral glia traveling in the antennal nerve (type ii), immunocytochemical labeling of glial cells in the cricket (Meyer et al., 1987) reveals that the 2 classes can be separated in that system on the basis of differential expression of antigens recognized by monoclonal antibodies. We do not know if populations of glial cells in Manduca can be separated immunologically; the antibodies used in cricket do not cross-react with Manduca (Edwards, personal communication). However, the possibility remains that the glial processes found inside the glomeruli represent a distinct subpopulation of glial cells. These cells could be functionally similar to those described by Raisman (1985) and Doucette (1989) that serve as an interface between peripheral and central glial cells in rat olfactory glomeruli.

\section{Conclusions}

In conclusion, this study has revealed that: (1) antennal (olfactory) axons appear to have the intrinsic ability to form protoglomeruli in Manduca, as they do in other systems; (2) these protoglomeruli consist primarily of whorls of antennal axons which apparently do not yet form synapses; (3) the ensemble of protoglomeruli forms a template for developing glomeruli; (4) an interaction between antennal axons and glial cells causes glia to surround the protoglomeruli; (5) the neurites of most antennal-lobe neurons invade the protoglomeruli a day or so after the protoglomeruli have formed and gradually develop their characteristic tufted arbors; (6) synapses, presumably including those between antennal axons and antennal-lobe neurons, form very quickly as neurites of the antennal-lobe neurons grow into the glomeruli; and (7) some projection neurons appear to have the intrinsic ability to form restricted, although not glomerulussized, arbors even in the absence of antennal axons. Thus, the development of glomeruli can be broken down into several steps that predict specific cellular interactions, separated in time. If certain of the interactions are prevented from occurring [i.e., if glial cells are removed (Oland et al., 1988; Oland and Tolbert, 1988 ) or if antennal axons are removed at different stages during glomerulus development (Tolbert and Sirianni, 1990)], then stable glomeruli do not form, and neurons develop aglomerular morphologies (Tolbert and Oland, 1990). Whether the production of a protoglomerular template and glial-cell changes underlie the formation of vertebrate olfactory glomeruli has not been explored.

The finding that neuronal elements form a protoglomerular template, then apparently halt their development for about a day while glial cells move into place, and then resume development lends further weight to our hypothesis that glial changes are necessary for the formation of glomeruli and the attendant formation of glomerular arbors by antennal-lobe neurons.

\section{References}

Anderson H, Edwards JS, Palka J (1980) Developmental neurobiology of invertebrates. Annu Rev Neurosci 3:97-139.

Anderson H, Tucker RP (1989) Spatial and temporal variation in the structure of the basal lamina in embryonic grasshopper limbs during pioneer neurone outgrowth. Development 106:185-194.
Brunjes PC, Frazier LL (1986) Maturation and plasticity in the olfactory system of vertebrates. $\mathrm{Br} \operatorname{Res} \operatorname{Rev} 11: 1-45$.

Bullock T, Horridge G (1965) Structure and function of the nervous system of insects. San Francisco: Freeman.

Camazine S, Hildebrand JG (1979) Central projections of antennal sensory neurons in mature and developing Manduca sexta. Soc Neurosci Abstr 5:155.

Carr VMcM, Farbman AI, Lidow MS, Colletti LM, Hempstead JL, Morgan JI (1989) Developmental expression of reactivity to monoclonal antibodies generated against olfactory epithelia. J Neurosci 9: 1179-1198.

Chambille I, Masson C, Rospars J (1980) The deutocerebrum of the cockroach Blaberus conifer Burm. Spatial organization of the sensory glomeruli. J Neurobiol 11:135-157.

Christensen TA, Hildebrand JG (1987a) Male-specific, sex pheromone-selective projection neurons in the antennal lobes of the moth Manduca sexta. J Comp Physiol A 160:553-569.

Christensen TA, Hildebrand JG (1987b) Functions, organization, and physiology of the olfactory pathways in the lepidopteran brain. In: Arthropod brain: its evolution, development, structure, and functions (Gupta AP, ed), pp 457-484. New York: Wiley.

Deitch JS, Rubel EW (1989) Rapid changes in ultrastructure during deafferentation-induced dendritic atrophy. J Comp Neurol 281:234258.

Doucette R (1989) Development of the nerve fiber layer in the olfactory bulb of mouse embryos. J Comp Neurol 285:514-527.

Farbman AI (1986) Prenatal development of mammalian olfactory receptor cells. Chem Senses 11:3-18.

Goodman LA, Covell DA, Model PG (1988) Regenerating afferent fibers stimulate the recovery of Mauthner cell dendritic branching in the axolotl. J Neurosci 8:3025-3034.

Graziadei PPC, Samanen DW (1980) Ectopic glomcrular structures in the olfactory bulb of neonatal and adult mice. Brain Res 187:467472.

Graziadei PPC, Levine RR, Monti-Graziadei GA (1979) Plasticity of connections of the olfactory sensory neuron: regeneration into the forebrain following bulbectomy in the neonatal mouse. Neuroscience 4:713-727.

Gregory WA, Edmondson JC, Hatten ME, Mason CA (1988) Cytology and neuron-glial apposition of migrating cerebellar granule cells in vitro. J Neurosci 8:1728-1738.

Hayashi JH, Hildebrand JG (1990) Insect central olfactory neurons in primary culture. J Neurosci 10:848-859.

Hildebrand JG (1985) Metamorphosis of the insect nervous system: influence of the periphery on the postembryonic development of the antennal sensory pathway in the brain of Manduca sexta. In: Model neural networks and behavior (Selverston A, ed), pp 129-148. New York: Plenum.

Hildebrand JG, Hall LM, Osmond BC (1979) Distribution of binding sites for ${ }^{125}$ I-labeled $\alpha$-bungarotoxin in normal and deafferented antennal lobes of Manduca sexta. Proc Natl Acad Sci USA 76:499-503.

Hinds JW (1972a) Early neuron differentiation in the mouse olfactory bulb. I. Light microscopy. J Comp Neurol 146:233-252.

Hinds JW (1972b) Early neuron differentiation in the mouse olfactory bulb. II. Electron microscopy. J Comp Neurol 146:253-276.

Hinds JW, Hinds PL (1976) Synapse formation in the mouse olfactory bulb. I. Quantitative methods. J Comp Neurol 169:15-40.

Homberg U, Montague RA, Hildebrand JG (1988) Anatomy of antenno-cerebral pathways in the brain of the sphinx moth Manduca sexta. Cell Tissue Res 254:255-281.

Homberg U, Christensen TA, Hildebrand JG (1989) Structure and function of the deutocerebrum in insects. Annu Rev Entomol 34:477501.

Hoy R, Cassaday G, Rollins S (1978) Absence of auditory afferents alters the growth pattern of an identified auditory interneuron. Soc Neurosci Abstr 4:115.

Kanzaki R, Arbas EA, Strausfeld NJ, Hildebrand JG (1989) Physi-

Figure 12. High-magnification electron micrographs of intercellular junctions. Glia-glia: $A$, probable desmosome; $B$, developing scalariform-like junction, displaying faint broad cross-striations at regular intervals (arrows). Neuron-glia: $C$, probable desmosome; $D$, possible tight junctions at arrowheads; $E$, junction characterized by rigidly parallel membranes and focculent material (without regular striations) in the intercellular space. The intercellular cleft is typically narrower than that of scalariform-like junctions. Scale bar, $100 \mathrm{~nm}$. 
ology and morphology of projection neurons in the antennal lobe of the male moth Manduca sexta. J Comp Physiol A 165:427-453.

Karnovsky M (1965) A formaldehyde-glutaraldehyde fixative of high osmolality for use in electron-microscopy. J Cell Biol 27:137A-138A.

Kent KS (1985) Metamorphosis of the antennal center and the influence of sensory innervation on the formation of glomeruli in the hawk moth Manduca sexta. PhD dissertation, Harvard University.

Kent KS, Harrow ID, Quartararo P, Hildebrand JG (1986) An accessory olfactory pathway in Lepidoptera: the labial pit organ and its central projections in Manduca sexta and certain other sphinx moths and silk moths. Cell Tissue Res 245:237-245.

Kent KS, Hoskins SG, Hildebrand JG (1987) A novel serotoninimmunoreactive neuron in the antennal lobe of the sphinx moth Manduca sexta persists throughout postembryonic life. J Neurobiol 18:451-465.

Konishi M, Akutagawa E (1985) Neuronal growth, atrophy, and death in a sexually dimorphic song nucleus in the zebra finch brain. Nature 315:145-147.

Lo Presti V, Macagno ER, Levinthal C (1974) Structure and development of neuronal connections in isogenic organisms: transient gap junctions between growing optic axons and lamina neuroblasts. Proc Natl Acad Sci (USA) 71:1098-1102.

Macagno E (1979) Cellular interactions and pattern formation in the development of the visual system of Daphnia magna (Crustacea, Brachiopoda) I. Interactions between embryonic retinular fibers and laminar neurons. Dev Biol 73:206-238.

Matsumoto SG, Hildebrand JG (1981) Olfactory mechanisms in the moth Manduca sexta: response characteristics and morphology of central neurons in the antennal lobes. Proc R Soc (Lond) 213:249277.

Meyer MR, Reddy GR, Edwards JS (1987) Immunological probes reveal spatial and developmental diversity in insect neuroglia. J Neurosci 7:512-521.

Monti-Graziadei GA, Stanley RS, Graziadei PPC (1980) The olfactory marker protein in the olfactory system of the mouse during development. Neuroscience 5:1239-1252.

Murphey R, Mendenhall B, Palka J, Edwards J (1975) Deafferentation slows the growth of specific dendrites of identified giant interneurons. J Comp Neurol 159:407-418.

Northcutt R, Braford M (1980) New observations on the organization and evolution of the telencephalon of Actinopterygian fishes. In: Comparative neurology of the telencephalon (Ebbesson S, ed), pp 41-98. New York: Plenum.

Oland LA, Tolbert LP (1987) Glial patterns during early development of antennal lobes on Manduca sexta: a comparison between normal lobes and lobes deprived of antennal axons. J Comp Neurol 255:196207.

Oland LA, Tolbert LP (1988) Effects of hydroxyurea parallel the effects of radiation in developing olfactory glomeruli in insects. J Comp Neurol 278:377-387.

Oland LA, Tolbert LP (1989) Patterns of glial proliferation during formation of olfactory glomeruli in an insect. Glia 2:10-24.

Oland LA, Tolbert LP, Mossman KL (1988) Radiation-induced reduction of the glial population during development disrupts the formation of olfactory glomeruli in an insect. J Neurosci 8:353--367.

Oland LA, Orr G, Tolbert LP (1989) The first events in the formation of insect olfactory glomeruli involve sensory axons and olfactory-lobe glia but not olfactory-lobe neurons. Soc Neurosci Abstr 15:445.

Raisman G (1985) Specialized neuroglial arrangement may explain the capacity of vomeronasal axons to reinnervate central neurons. Neuroscience 14:237-254.
Rakic P, Sidman R (1973) Organization of cercbcllar cortcx sccondary to deficit of granule cells in weaver mutant mice. J Comp Neurol 152: 133-162.

Sanes JR, Hildebrand JG (1976) Structure and development of antennae in a moth, Manduca sexta. Dev Biol 51:282-299.

Sanes JR, Hildebrand JG, Prescott DJ (1976) Differentiation of insect sensory neurons in the absence of their normal synaptic targets. Dev Biol 52:121-127.

Sanes JR, Prescott DJ, Hildebrand JG (1977) Cholinergic neurochemical development of normal and deafferented antennal lobes during metamorphosis of the moth, Manduca sexta. Brain Res 119:389-402.

Schildberger K, Wohlers DW, Schmitz B, Kleindienst H-U, Huber F (1986) Morphological and physiological changes in central auditory neurons following unilateral foreleg amputation in larval crickets. $\mathbf{J}$ Comp Physiol A 158:291-300.

Schneiderman AM, Hildebrand JG, Jacobs JJ (1983) Computer-aided morphometry of developing and mature antennal lobes in the moth Manduca sexta. Soc Neurosci Abstr 9:834.

Shankland M, Bentley D, Goodman CS (1982) Afferent innervation shapes the dendritic branching pattern of the medial giant interneuron in grasshopper embryos raised in culture. Dev Biol 92:507-520.

Sharp F, Kauer J, Shepherd G (1977) Laminar analysis of 2-deoxyglucose uptake in olfactory bulb and olfactory cortex of rabbit and rat. J Neurophysiol 40:800-813.

Shatz CJ, Luskin MB (1986) The relationship between geniculocortical afferents and their cortical target cells during development of the cat's primary visual cortex. J Neurosci 6:3655-3668.

Shepherd $G$ (1970) The olfactory bulb as a simple cortical system: expcrimental analysis and functional implications. In: The ncurosciences: second study program (Schmitt FO, ed), pp 539-552. New York: Rockefeller UP.

Steindler DA, Cooper NGF, Faissner A, Schachner M (1989) Boundaries defined by adhesion molecules during development of the cerebral cortex: the $\mathrm{J} 1 /$ tenascin glycoprotein in the mouse somatosensory cortical barrel field. Dev Biol 131:243-260.

Tolbert LP (1989) Afferent axons from the antenna influence the number and placement of intrinsic synapses in the antennal lobes of Manduca sexta. Synapse 3:83-95.

Tolbert LP, Hildebrand JG (1981) Organization and synaptic ultrastructure of glomeruli in the antennal lobes of the moth Manduca sexta: a study using thin sections and freeze-fracture. Proc R Soc (Lond) 213:279-301.

Tolbert LP, Oland LA (1989) A role for glia in the development of organized neuropilar structures. Trends Neurosci 12:70-75.

Tolbert LP, Oland LA (1990) Glial cells form boundaries for developing insect olfactory glomeruli. Exp Neurol (in press).

Tolbert LP, Sirianni PA (1990) The requirement for olfactory axons in the induction and stabilization of olfactory glomeruli in an insect. $\mathrm{J}$ Comp Neurol (in press).

Tolbert LP, Matsumoto SG, Hildebrand JG (1983) Development of synapses in the antennal lobes of the moth Manduca sexta during metamorphosis. J Neurosci 3:1158-1175.

Tosney KW, Landmesser LT (1985) Development of the major pathways of neurite outgrowth in the chick hindlimb. Dev Biol 109:193214.

Wigglesworth V (1972) The principles of insect physiology, pp 181185. London: Chapman and Hall.

Wise SB, Jones EG (1978) Developmental studies of the thalamocortical and commissural connections in the rat somatic sensory cortex. J Comp Neurol 175:187-208. 